\title{
A situation analysis of the maternal and child health/family planning (MCH/FP) program in Botswana
}

\author{
Benjamin Baakile \\ Lucy Sejo Maribe \\ Baker Ndugga Maggwa \\ Population Council \\ Robert A. Miller \\ Population Council
}

Follow this and additional works at: https://knowledgecommons.popcouncil.org/departments_sbsr-rh

Part of the Family, Life Course, and Society Commons, International Public Health Commons, and the Maternal and Child Health Commons

How does access to this work benefit you? Let us know!

\section{Recommended Citation}

Baakile, Benjamin, Lucy Sejo Maribe, Baker Ndugga Maggwa, and Robert A. Miller. 1996. "A situation analysis of the maternal and child health/family planning (MCH/FP) program in Botswana," Africa OR/TA Project II Final Report. Gabarone: Population Council and Ministry of Health MCH/FP Unit. 


\section{A Situation Analysis of the Maternal and Child Health/Family Planning (MCH/FP) Program in Botswana}

MCH/FP Unit, Family Health

Division,

Ministry of Health,

Republic of Botswana

Benjamin Baakile

Lucy Maribe
Operations Research/ Technical Assistance Africa Project II The Population Council

Baker Ndugga Maggwa

Robert A. Miller 


\section{The Population Council}

The Population Council seeks to help improve the well-being and reproductive health of current and future generations around the world and to help achieve a humane, equitable, and sustainable balance between people and resources. The Council analyzes population issues and trends; conducts biomedical research to develop new contraceptives, works with public and private agencies to improve the quality and outreach of family planning and reproductive health services. helps governments to influence demographic behavior; communicates the results of research in the population field to appropriate audiences; : and helps build research capacities in developing countries. The Council, a nonprofit, non-governmental research organization established in 1952, has a multinational Board of Trustees; its New York headquarters supports a global network of regional and country offices.

This project was supported by the Population Council's Africa Operations Research and Technical Assistance Project II, Project No. CCP 303-C-00-3008-00, and by the Population Council's Cooperative Agreement No. CCP-3050-A-00-4013-00, both funded by the United States Agency for International Development (USAID). 


\section{Acknowledgments}

The Botswana MCH/FP Situation Analysis Study was undertaken with substantial inputs from various organizations and many people whose assistance is gratefully acknowledged. In preparing for and undertaking the Situation Analysis Study, the $\mathrm{MCH} / \mathrm{FP}$ unit and The Population Council OR/TA project staff worked very closely with members of the District Health Teams, UNFPA, UNICEF, the Health Research Unit at the Ministry of Health and the Department of Primary Health Care at the Ministry of Local Government. Special thanks go to all the staff from these organizations who helped with the development and review of the data collection methodology and instruments, interpretation of the data collected through this exercise and formulation of the programmatic recommendations. At the clinics which participated in the study our special thanks go to the clinic staff for their cooperation and the assistance they extended to the researchers during the study. We are grateful to the clients for having accepted to participate in the study and for the cooperation they extended to the study team.

Special mention must be made of Mr. Scott Stewart, the Health, Population and Nutrition Advisor at the USAID Mission in Botswana, for his contribution to the whole exercise. He provided the necessary administrative and logistical support and always made time available for consultation with the study team whenever this was necessary. Special thanks also go to Mr. Moses Mukasa the UNFPA Country Director for the active role and support he provided to the project. The field work would not have been possible without the participation of the University of Botswana students who sacrificed their vacation to help with the data collection. Their role in the study is gratefully acknowledged. Mentioning everybody who contributed to the success of this study is not possible but their roles are acknowledged. 


\section{List of abbreviations}

\begin{tabular}{|c|c|}
\hline AIDS & Acquired Immune Deficiency Syndrome \\
\hline $\mathrm{ANC}$ & Antenatal Care \\
\hline API & Assessment of Program Impact \\
\hline $\mathrm{BCG}$ & Bacilli Calmette Guerin \\
\hline BFHSII & Botswana Family Health Survey 11 \\
\hline BOSTPA & Botswana Population Assistance Project \\
\hline $\mathrm{BP}$ & Blood pressure \\
\hline CAFS & Center for African Family Studies \\
\hline $\mathrm{CDC}$ & Centers for Disease Control \\
\hline $\mathrm{CHN}$ & Community Health Nurse \\
\hline CYP & Couple Years of Protection \\
\hline DHT & District Health Team \\
\hline DMO & District Medical Officer \\
\hline DPT & Diphtheria, Pertussis and Tetanus \\
\hline EPI & Expanded Program of Immunization \\
\hline EXAM & Examination \\
\hline FNP & Family Nurse Practitioner \\
\hline FWE & Family Welfare Educator \\
\hline $\mathrm{FP}$ & Family Planning \\
\hline HIV & Human Immune Deficiency Virus \\
\hline IEC & Information, Education and Communication \\
\hline IUCD & Intrauterine (Contraceptive) Device \\
\hline JSI & John Snow Inc. \\
\hline LAM & Lactitional Amenorrhea \\
\hline $\mathrm{MCH}$ & Maternal and Child Health \\
\hline MIS & Management Information System \\
\hline $\mathrm{MOH}$ & Ministry of Health \\
\hline NACP & National AIDS Control Program \\
\hline OR/TA II & Africa Operations Research and Technical Assistance Project II \\
\hline RPR & Rapid Plasma Reagin \\
\hline SA & Situation Analysis \\
\hline SDP & Service Delivery Point \\
\hline SNS & Senior Nursing Sister \\
\hline STI & Sexually Transmitted Infections \\
\hline STD & Sexually Transmitted Diseases \\
\hline TA & Technical Assistance \\
\hline UNFPA & United Nations Population Fund \\
\hline UNICEF & United Nations Children's Fund \\
\hline USAID & United States Agency for International Development \\
\hline VDRL & Venereal Disease Research Laboratory (syphilis test) \\
\hline
\end{tabular}




\section{Contents}

Executive Summary

Background I

Problem identification, definition and 'justification 3

Objectives $\quad 4$

Ultimate objective $\quad 4$

Immediate objectives $\quad 4$

Data collection and analysis $\quad 5$

Description of health facilities and sampling plan 5

Data collection, instruments and training $\quad 5$

Fieldwork $\quad 7$

$\begin{array}{ll}\text { Data processing and analysis } & 7\end{array}$

$\begin{array}{ll}\text { Dissemination and use of information } & 7\end{array}$

$\begin{array}{ll}\text { Data interpretation workshop } & 7\end{array}$

National dissemination workshop $\quad 8$

$\begin{array}{lr}\text { Principal findings and conclusions } & 9\end{array}$

$\begin{array}{lr}\text { Study population and characteristics } & 9\end{array}$

Functional status of subsystems at health facilities 11

$\begin{array}{ll}\text { Infrastructure } & 11\end{array}$

$\begin{array}{ll}\text { Equipment and supplies } & 11\end{array}$

Laboratory and screening facilities for ST1s and HIV/AIDS 12

IEC Materials and activities $\quad 13$

$\begin{array}{ll}\text { Contraceptive supplies and logistic-, } & 14\end{array}$

Management and supervision 15

Record keeping $\quad 16$

Storage facilities and conditions 16

Service provider preparedness to provide

MCH/FP and STI/HIV/AlDS services 17

$\begin{array}{ll}\text { Availability of staff } & 17\end{array}$

$\begin{array}{ll}\text { Staff experience } & 17\end{array}$

$\begin{array}{ll}\text { Staff training } & 19\end{array}$

Staff skills, practices and competence 20

$\begin{array}{ll}\text { Accessibility of services } & 23\end{array}$

Opening times $\quad 23$

Availability of services $\quad 24$

$\begin{array}{ll}\text { Availability of signs advertising services } & 25\end{array}$ 
$\begin{array}{ll}\text { Quality of care provided } & 25\end{array}$

Interpersonal relations $\quad 26$

$\begin{array}{ll}\text { Clinical assessment of clients } & 26\end{array}$

$\begin{array}{ll}\text { Information given to clients } & 30\end{array}$

Choice of methods 31

Constellation of services $\quad 33$

Need for reproductive health services $\quad 35$

$\begin{array}{ll}\text { Unmet contraceptive needs } & 35\end{array}$

Need for STI and HIV/AIDS services $\quad 36$

Conclusions and programmatic recommendations 39 


\section{Executive Summary}

\section{Introduction}

Botswana, in common with nearly all other sub-Saharan African countries, has a rapid annual population growth rate $(3.5 \%)$ and a total fertility rate which, although decreasing, remains high at 4.3 births per woman. It also has one of the highest levels of contraceptive use in sub-Saharan Africa (29\% among all women in 1988, estimated at $32 \%$ in 1991), achieved without an official population policy or a separate family planning program. Infant and under-5 mortality rates have fallen by more than $60 \%$ in the period 1971-1988 (to 37 and 52 per 1,000 live births, respectively), yet maternal mortality remains high at 200 per 100,000 live births.

The Government of Botswana has developed an extensive network of health care facilities which provide services through an integrated approach. In relation to family planning services, the most recent Family Health Survey (FHS 11) revealed that the Ministry of Health (MOH) provided services to $94.2 \%$ of all current contraceptive users, and is thus the dominant provider of modem contraceptive methods. Within the $\mathrm{MOH}$, family planning service delivery is overseen by the MCH/FP Unit of the Family Health Division.

Over half the women surveyed in the 1988 FHS 11 currently using a modem method were using the pill, one third the IUCD, and the remainder the injectable, sterilization and the condom. Recent service statistics from health facilities suggest, however, that these proportions are changing, in that the condom is now becoming more widely used than the pill and that the proportion of IUCD users is decreasing. Family planning services are available daily at all three levels of the $\mathrm{MOH}$ system (i.e., hospitals, clinics, health posts), although clinical methods (IUCD, injectable) are not normally available at the Health Post level (staffed by Family Welfare Educators and/or Enrolled Nurses), and sterilizations can only be undertaken by doctors in a few hospitals. Access to contraceptives is quite good in that $85 \%$ of the population is within $15 \mathrm{kms}$ of one of the health care facilities providing these services.

Services for managing sexually transmitted diseases (STDS) have recently undergone a substantial change in Botswana, with the introduction in 1992 of the Syndromic Approach to the management of STDS. Prior to the introduction of this approach, STD patients were treated through diagnosis of specific diseases by referral of samples for laboratory testing. With the Syndromic Approach, a client is diagnosed, at the point of contact, through history taking and categorization into a broad syndrome according to a clinical algorithm; treatment is then made by syndrome rather than specific disease. Training in this approach to date has been at the district level and it is expected that staff at all SDPs will be trained in the near future. The availability of drugs for treatment is not a major problem in Botswana.

There is also concern about a rapid increase in the number of persons infected with HIV, estimated to be about 92,000 in 1993 (out of a population of 1.3 million); or 
one in seven of the sexually active population. The second HIV Sentinel Surveillance survey in April 1993 revealed a 22.5\% HIV sero-prevalence rate at seven sites, and a rate of 31.9\% among males with other sexually-transmitted diseases (STDs). Between 1993 and 1995 the HIV sero-prevalence among antenatal women rose from $22.5 \%$ to $32.5 \%$.

Although the Government of Botswana continues to make tremendous efforts to meet the need for family planning, STD and AIDS services in the country, there remains a large unmet need for these services. The need for effective family planning services is evidenced by the many women reporting in the FHS 11 that their last birth was unwanted (48\%) and that they want to space or have no more births in the future (45\%). For STD/AIDS services, the number of STD diagnoses increased by $26 \%$ in the years 1988 91, HIV sero-prevalence among STD clients was up by more than $30 \%$, and in urban areas HIV infection among sexually active adults has doubled over the last year

The BOTSPA Project is USAID's approach to strengthening MCH/FP and S'I'D/AIDS services, with the overall purpose "to improve the quality and availability of FP/STD services and expand AIDS prevention measures". The project consists of five broad interventions, three of which are directly concerned with strengthening the delivery of FP/STD/AIDS services through health care facilities:

1) in-service training for $\mathrm{MCH} / \mathrm{FP}$ personnel, focussing on clinical skills, $\mathrm{FP} / \mathrm{STD}$ counseling reporting and use of data;

2) Strengthening the Management Information System (MIS) for FP services to enable .multiple indicators of contraceptive prevalence, commodity requirements and stock levels to be produced;

3) Production and distribution of IEC Materials for FP and the prevention of STDS.

The BOTSPA Project provides, therefore, an exciting opportunity to observe and evaluate the introduction of interventions designed to improve the quality and accessibility of FP services, STD management and AIDS education activities simultaneously.

\section{Problem identification, definition and justification}

The Botswana $\mathrm{MOH}$ believes that the quality of services provided influences the acceptance and continued use of FP methods and STD services, and therefore would like to be able to measure the impact of the BOTSPA interventions on the quality of service provided, and consequently the effect that improving the quality of service delivery has on reproductive health behavior. Data from this situation analysis provides information on the quality of services being provided at the start of the BOTSPA interventions. This information can be used as baseline measurements in the future to monitor and assess the impact of the BOTSPA interventions on the quality of MCH/FP and STI/HIV services. A second Situation Analysis Study looking at the same measurements was to be undertaken after two years of the BOTSPA intervention, but due to funding constraints this may not take place. The second Situation Analysis would have facilitated the measurement of changes resulting from the BOTSPA interventions. 
The $\mathrm{MOH}$ also expressed a need to measure routinely the service quality provided. It has experimented previously with in-depth supervisory visits as one approach to doing this, but would like to develop a systematic and sustainable approach to regularly measure service quality which can be incorporated into its overall MIS. Consequently, the MOH has requested that the Africa OR/TA II Project assist in developing and testing an appropriate quality assessment mechanism. This Situation Analysis Study provides the baseline data to be used in the development of the quality assessment and monitoring mechanisms in a separate activity.

\section{Study population}

A total of 186 randomly selected facilities comprising 20 hospitals, 121 clinics and 45 health posts were surveyed in this study. Interviews were conducted with 451 staff members providing MCH/FP services within these facilities. Observations of interactions between clients and service providers were carried out for 406 clients receiving family planning services in the study facilities. Exit interviews were undertaken for 386 clients receiving family planning and 724 clients receiving $\mathrm{MCH}$ services during the study period.

\section{Results}

Infrastructure: Most of the health facilities surveyed, had the basic physical infrastructure required to provide good quality MCH/FP and STI/HIV/AIDS services. However, many facilities (40\%) lacked electricity of any kind and $16 \%$ did not have areas designated as waiting areas or functioning toilets for use by clients.

Supplies, and equipment: The basic equipment and supplies necessary for the provision of the basic MCH/FP and STI/AIDS services were available in most of the facilities. Many facilities (590/o) did not have a functioning angle poise lamp or torch that could be used as a source of light during clinical examinations and procedures. Equipment required for IUCD insertion and removal was lacking at a significant number of the facilities.

IIEC Materials and activities: IEC materials and activities are generally lacking at most of the facilities. For example, less than $30 \%$ of the facilities had any flip charts on any $\mathrm{MCH} / \mathrm{FP}$ and STI/HIV/AIDS services. During the study period group health talks were held for the $\mathrm{MCH} / \mathrm{FP}$ clients at only 27 of the 186 facilities surveyed. More than $40 \%$ of the facilities did not have any brochures or pamphlets on ST1s and HVI/AIDS. Only $25 \%$ of the $\mathrm{MCH}$ clients who were not using any contraceptive method received any information about family planning during this clinic visit. Data from the study show the many missed opportunities to inform $\mathrm{MCH} / \mathrm{FP}$ clients about other major reproductive health issues.

Availability of contraceptive methods: The pill, condom and Depo-Provera are provided at more than $90 \%$ of the health facilities covered by the study. Tubal ligation is provided at only eight of the 20 hospitals surveyed. Less than $10 \%$ of the facilities were 
providing spermicides while $73 \%$ provided the IUCD. The variety of methods available at the health facilities covered in the study is limited and as such narrows the choices that clients have. Besides the limited choice, some facilities do not have a good contraceptive management system. A number of facilities did not have supplies or had recently experienced a stockout of the methods they provide while others had expired stocks. For example, $13 \%$ of the health facilities did not have a supply of condoms on the day of the survey while $23 \%$ had experienced a stockout of condoms in the six months preceding the survey.

Management and supervision: Most of the facilities (92\%) surveyed had been visited by a supervisor in the six months preceding the study. The DMO was the person who had visited the largest number of facilities compared to all the other cadres of staff with supervision responsibilities. The activities undertaken during the supervision visits varied a lot and depended on the cadre and professional background of the staff undertaking the visit. This is due to the lack of a standardized checklist and guidelines to be used by the supervisors. As a result, it is difficult to compare findings by the different supervisors and between the different facilities. The manner in which supervision is carried out now does not facilitate the monitoring of the $\mathrm{MCH} / \mathrm{FP}$ program as whole.

Record Keeping: Most facilities keep a record of their activities and the staff use this information to prepare reports that they submit monthly to a higher authority. Although most of the facilities kept an inventory/stock book, these were not well maintained by many facilities. Records are an important source of information for management and if they are not well kept, monitoring of program activities becomes impossible.

Service provider training, skills and practices: Most of the staff have been trained in the provision of MCH/FP and STI/HIV/AIDS services through basic, post basic and refresher courses. Despite the training the staff have had, many of them still lack adequate skills for determining the reproductive health needs of clients seeking $\mathrm{MCH}$, FP, STD and HIV/AIDS services. For example, they do not obtain a good medical history and/or carry out a proper clinical assessment of clients requiring family planning services and those requiring treatment for a vaginal discharge. Although the FWEs are expected to provide basic MCH/FP services at the Health Posts, few had basic training in antenatal, postnatal, STI and HIV/AIDS services. The findings from the study suggest that there is a need to re-examine the basic training programs for these staff and to conduct refresher training for most of them to update and improve on their skills.

Accessibility of services: Most of the clinics open at $7.30 \mathrm{a} . \mathrm{m}$. and close after $4.30 \mathrm{p}$. $\mathrm{m}$. for five days a week. Although most clinics open at $7.30 \mathrm{a}$. m., the staff normally start providing services to clients at $8.30 \mathrm{a} . \mathrm{m}$. and most family planning clients are served in the morning with most facilities seeing the last family planning client by I $1.30 \mathrm{a}$. m. On average, FP clients waited for 50 minutes at the health facilities before being attended. Most of the clients live within walking distance to the health facilities where they receive MCHIFP services. Many facilities do not provide all the MCH/FP services on a daily basis. For example, $29 \%$ of the facilities were not providing antenatal care on 
the day of the survey. Although $65 \%$ and more than $90 \%$ of the facilities provide HIV/AIDS and STI services, respectively, less than $10 \%$ of the clients were aware that they could receive these services at the facilities they had visited for MCH/FP services. Signs or billboards announcing the availability of MCH, FP, STD and HIV/AIDS services are absent at most of the clinics.

Quality of Services received by MCH/FP clients: The majority of the clients were received in a friendly manner by the service providers. Generally the clients were satisfied with their visits to the health facilities. However, a significant number felt that the consultation time was short and the service providers did not give them an opportunity to ask questions that were important to them. Some clients said that the consultation did not take place in an environment that ensured privacy for them.

The history taken and clinical procedures performed for the clients was not adequate to facilitate proper assessment of the clients' needs and suitability of the methods and other interventions by the service providers. The situation was worse for the repeat family planning clients. In a number of cases it was found that the service providers were not following the instructions in the service manuals while providing the $\mathrm{MCH} / \mathrm{FP}$ and STI/HIV/AIDS services.

Clients are not informed about all the available contraceptive methods and are given inadequate information about the methods that they choose to use. This limits the clients' ability to make informed choices and denies them information that would have helped in managing the methods they choose to use.

Service providers still restrict the use of the pill, IUCD and Depo-Provera based on age and parity. Some service providers said that they would not provide condoms to married women without consent from their spouses. Age and parity are listed in the Policy Guideline and Service Standards Manual of 1987 as conditions to be considered before giving clients these methods. A revised manual which eliminates most of these barriers had not been circulated at the time of this study.

Need for reproductive health services: Although most of the clients receiving $\mathrm{MCH}$ services from the health facilities are aware of the various contraceptive methods, a wide gap still exists between the proportion aware and that using the methods. More than $40 \%$ of the clients receiving $\mathrm{MCH}$ services and not using a contraceptive method at the time of the study did not want to have a child within the next two years. Although $48 \%$ and $38 \%$ of women receiving $\mathrm{MCH}$ and $\mathrm{FP}$ services, respectively, did not want to have any more children in the future, very few of these women were using a permanent or long-term method for contraception. These findings suggest a wide range of unmet contraceptive needs for clients receiving $\mathrm{MCH} / \mathrm{FP}$ service from the health facilities.

Data from the study show that the majority of women receiving $\mathrm{MCH} / \mathrm{FP}$ services at these health facilities have poor knowledge of the symptoms and modes of transmission of ST1s and HIV/AIDS. The study also found that I $1 \%$ and $20 \%$ of the clients receiving $\mathrm{MCH}$ and $\mathrm{FP}$ service had sex with a new partner in the twelve months 
preceding the study; two-thirds of the respondents who reported having had sex with a new partner said that they used a condom the first time they had sex with the new partner. These findings suggest that there is a need for strengthening IEC activities on STIs and HIV/AIDS for women attending the health facilities for MCH and FP services.

Laboratory services: Screening antenatal women for syphilis and family planning clients for cervical cancer are major components of the MCH/FP program. However, data from this study shows that very few health facilities have easy access to laboratories to carry out these tests. Syphilis, HIV and Pap Smear testing Facilities are available at fewer than $20 \%$ of the facilities. The study also found that test results from the referral centers take 4-5 days for syphilis and I I- 18 days for HIV and Pap Smear tests to get back to the referring health facility. These findings mean that clients have to make two separate visits one for the specimen to be obtained and the other to get the test results and treatment where necessary. This is no longer necessary as simple and rapid tests which can be carried out at the health facilities and provide results immediately for many of these tests are now available.

Immunization services: Although the majority (over 85\%) of the health facilities provide all the basic immunization services, the study found that $16 \%, 22 \%$ and $12 \%$ of the facilities which provide these services did not have a supply of BCG, polio and measles vaccines, respectively, on the day of the survey. Many of the health facilities $(50 \%)$ did not have a functioning EPI refrigerator on the day the facility was visited. 


\section{Background}

Botswana, in common with nearly all other sub-Saharan African countries, has a rapid annual population growth rate $(3.50 / \mathrm{o})$ and a total fertility rate which, although decreasing, remains high at 4'3 births per woman '.' It also has one of the highest levels of contraceptive use in sub-Saharan Africa (29\% among all women in 1988, estimated at $32 \%$ in 1991 ), achieved without an official population policy or a separate family planning program. Infant and under-5 mortality rates have fallen by more than $60 \%$ in the period 1971-1988 (to 37 and 52 per 1,000 live births, respectively), yet maternal mortality remains high at 200 per 100,000 live births.

The Government of Botswana has developed an extensive network of health care facilities which provide services through an integrated approach. In relation to family planning services, the most recent Family Health Survey (FHS 11) ${ }^{2}$ revealed that the Ministry of Health (MOH) provided services to $94.2 \%$ of all current contraceptive users, and is thus the dominant provider of modern contraceptive methods ${ }^{3}$.' Within the $\mathrm{MOH}$, family planning service delivery is overseen by the MCH/FP Unit of the Family Health Division.

Over half the women surveyed in the 1988 FHS 11 currently using a modern method were using the pill, one third the IUCD, and the remainder the injectable, sterilization and the condom. Recent service statistics from health facilities suggest, however, that these proportions are changing, in that the condom is now becoming more widely used than the pill and that the proportion of IUCD users is decreasing ${ }^{4}$.' Family planning services are available daily at all three levels of the MOH system (i.e., hospitals, clinics, health posts), although clinical methods (IUCD, injectable) are not normally available at the Health Post level (staffed by Family Welfare Educators and/or Enrolled Nurses), and sterilizations can only be undertaken by doctors in a few hospitals. Access to contraceptives is quite good in that $85 \%$ of the population is within $15 \mathrm{kms}$ of one of the health care facilities providing these services.

Services for managing sexually transmitted diseases (STDS) have recently undergone a substantial change in Botswana, with the introduction in 1992 of the Syndromic Approach to the management of STDS ${ }^{5}$.' Prior to the introduction of this approach, STD $^{5}$ patients were treated through diagnosis of specific diseases by referral of samples for laboratory testing. With the Syndromic Approach, a client is diagnosed, at the point of contact, through history taking and

1

I The data in this section are drawn largely from the recent UNFPA assessment: UNFPA (1 992) Botswana: Programme Review and Strategy Development Report, UNFPA, New York.

2 Central Statistics Office, Division of Family Health \& Macro Systems Inc. (1 989) Botswana Family Health Survey II. 1988.

3 It is anticipated that the Proportion of users served by NG0s, private doctors and pharmacies is probably higher now and will continue to grow as medical aid schemes are introduced and the social marketing program expands.

Central Statistics office (1 993) Stats Brief: Health Statistics 1987-1992. Central Statistics Office, Gaborone, BotswanaNational Aids Control programme (1 992) The Management of Sexually Transmitted Diseases in Botswana: A Manual for Health Workers, NACP, Ministry of Health, Gaborone, Botswana. 
categorization into a broad syndrome according to a clinical algorithm. treatment is then made by syndrome rather than specific disease. Training in this approach to date has been at the district level and it is expected that staff at all SDPs will be trained in the near future. The availability of drugs for treatment is not a major problem in Botswana.

There is also concern about a rapid increase in the number of persons infected with HIV, estimated to be about 92,000 in 1993 (out of a population of 1.3 million); or one in seven of the sexually active population. The second HIV Sentinel Surveillance survey in April 1993 revealed a 22. 5\% HIV sero-prevalence rate at seven sites, and a rate of $31.9 \%$ among males with other sexually-transmitted diseases (STDs) ${ }^{6}$.' Between 1993 and 1995 the HIV sero-prevalence among antenatal women rose from $22.5 \%$ to $32.5 \%$.

The National AIDS Control Programme (NACP) was established in 1989 and many activities are being undertaken to address the AIDS epidemic. A National AIDS Policy has been adopted to guide a multi-sectoral response to the epidemic, with the Ministry of Health, through its AIDS/STD Unit, taking the lead role in prevention and care activities. Besides epidemiological surveillance and other research, the NACP is following three broad strategies:

- prevention of sexual transmission through IEC activities, control of STDS, and condom promotion;

- prevention of transmission through blood by ensuring that all blood and its products used in health facilities are screened for HIV

- care of persons with HIV/AIDS, including clinical management of HIV/AIDS, homebased care support, and counseling for support of persons with HIV/AIDS and their families.

Although the Government of Botswana continues to make tremendous efforts to meet the need for family planning, STD and AIDS services in the country, there remains a large unmet need for these services. The need for effective family planning services is evidenced by the many women reporting in the FHS II that their last birth was unwanted $(48 \%)$ and that they want to space or have no more births in the future $(45 \%)$. For STD/AIDS services, the number of STD diagnoses increased by $26 \%$ in the years 1988 91, HIV sero-prevalence among STD clients was up by more than 300/o, and in urban areas HIV infection among sexually active adults has doubled over the last year. ${ }^{7}$

The 1991 UNFPA Programme Review identified a number of constraints to strengthening family planning service delivery, notably:

- $10-20 \%$ of health facilities do not have integrated MCH/FP services, although integration has been Government policy for several years; 
- Staff are insufficiently trained in family planning (FP) to fulfill the human resource needs, particularly at the Enrolled Nurse level;

- limited access to services amongst certain sectors for the population, notably adolescents and those living long distances from health facilities;

- poor processing and use of service statistics;

- high FP method discontinuation rates for health reasons and method failure suggest that the quality of client-provider interactions could be improved.

These and other constraints were highlighted in the background and justification for the USAID-supported Botswana Population Assistance (BOTSPA) Project. The BOTSPA Project is USAID's approach to strengthening MCH/FP and SID/AIDS services, with the overall purpose "to improve the quality and availability of FP/STD services and expand AIDS prevention measures". The project consists of five broad interventions, three of which are directly concerned with strengthening the delivery of FP/STD/AIDS services through health care facilities:

1) In-service training for $\mathrm{MCH} / \mathrm{FP}$ personnel, focussing on clinical skills, FP/STD counseling reporting and use of data;

2) Strengthening the Management Information System (MIS) for FP services to enable multiple indicators of contraceptive prevalence, commodity requirements and stock levels to be produced:

3) Production and distribution of IEC Materials for FP and the prevention of STDS.

Implementation of these interventions began in April 1994 through a contract with Cambridge Consulting Corporation to provide technical assistance to the Botswana $\mathrm{MOH}$; the Project completion date is September 30, 1996. The BOTSPA Project provides, therefore, an exciting opportunity to observe and evaluate the introduction of interventions designed to improve the quality and accessibility of FP services, STD management and AIDS education activities simultaneously.

\section{Problem identification, definition and justification}

The Botswana $\mathrm{MOH}$ believes that the quality of services provided influences the acceptance and continued use of FP methods and STD services, and therefore would like to be able to measure the impact of the BOTSPA interventions on the quality of service provided, and consequently the effect that improving the quality of service delivery has on reproductive health behavior. Data from this situation analysis provides information on the quality of services being provided at the start of the BOTSPA interventions. This information can be used as baseline measurements in the future to monitor and assess the impact of the BOTSPA interventions on the quality of MCH/FP and STI/IHV services. A second Situation Analysis Study looking at the same measurements was to be undertaken after two years of the BOTSPA intervention, but due to funding constraints this may not take place. The second Situation Analysis would have facilitated the measurement of changes resulting from the BOTSPA interventions. 
The MOH also expressed a need to measure routinely the service quality provided. .It has experimented previously with in-depth supervisory visits as one approach to doing this, ${ }^{2}$ but would like to develop a systematic and sustainable approach to regularly measure service quality which can be incorporated into its overall MIS. Consequently, the $\mathrm{MOH}$ has requested that the Africa OR/TA II Project assist in developing and testing an appropriate quality assessment mechanism. This Situation Analysis Study provides the baseline data to be used in the development of the quality assessment and monitoring mechanisms in a separate activity.

This study also provided the opportunity to strengthen the Situation Analysis methodology. This relatively new operations research approach has been developed and pioneered in the Africa region by The Population Council and has proved to be useful in a variety of circumstances in several different countries. Its utilization in Botswana through this study enabled the methodology to be developed further in a number of ways:

- development of new modules to collect data on STD management and AIDS prevention activities, thus making the methodology more relevant for broader reproductive health care programs;

- increase in the level of participation of program managers in the implementation of the approach and utilization of results.

\section{Objectives}

\section{Ultimate objective:}

To provide baseline data for evaluating the impact of improving the quality of FP/STD/AIDS service delivery on reproductive behavior.

\section{Immediate objectives:}

1) to document the quality of care provided to clients receiving family planning services through the MCH/FP clinics.

2) to document the level of preparedness (availability and functional status) of the $\mathrm{MC} / \mathrm{FP}$ program's major subsystems to provide MCH/FP, STI and HIV/AIDS services using the integrated approach.

3) to determine the need for MCH/FP and STI/I-HV/AIDS services among populations receiving these services at the health facilities.

4) to document the integration of FP, STD management and AIDS prevention procedures at the clinic level. 


\section{Data collection and analysis}

\section{Description of health facilities and sampling plan}

According to the available service statistics, there were 29 hospitals, 200 clinics and 310 health posts providing $\mathrm{MCH} / \mathrm{FP}$ services in Botswana at the time of the study Using standard sample size determination procedures and the number of repeat family planning clients for weighting, it was found that a sample size of 223 facilities comprising of 24 hospitals, 136 clinics and 63 health posts would be appropriate for the study. A listing of the facilities to be visited was prepared using the random multi-stage sampling procedures. Some facilities selected for the study refused to participate while others were not providing family planning services and therefore were excluded from the study' In a few instances, accessing some selected facilities was impossible given the nature of the roads. A total of 186 facilities were visited during the field work including 20 hospitals, 121 clinics and 45 health posts (Figure 1)

\section{Figure 1 Health Facilities Surveyed}

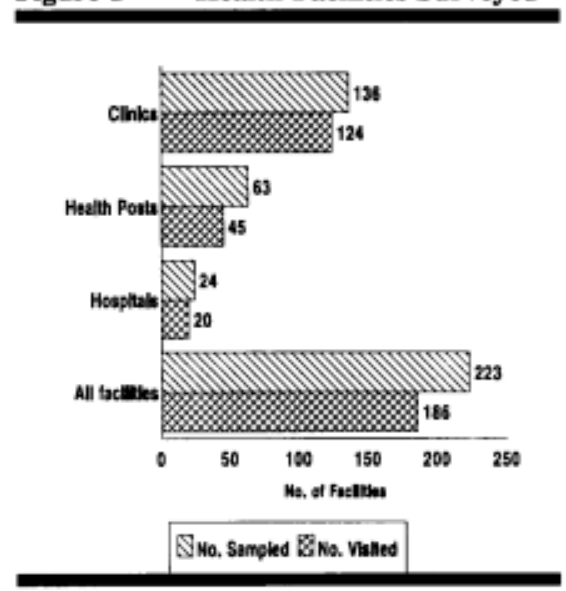

\section{Data collection, instruments and training}

At each of the health facilities visited during the study, information was collected through observations and interviews and an inventory of the available facilities, equipment and supplies was prepared. The basic data collection instruments used had already been developed and tested elsewhere ${ }^{8}$, but were customized for application in the Botswana situation during a two-day planning workshop. The instruments included:

- Inventory for Facilities Available and Services Provided at the Health Facility

- Interview Schedule for Staff Providing Family Planning at the Health Facility

- Observation Guide and Exit Interview schedules for Interaction Between Consenting Family Planning Clients and Service Provider

- Exit interview schedule for Female MCH Clients attending the Health Facility

$8 \quad{ }^{3}$ See The Population Council (1 994) Draft Guidelines and Instruments for Conducting a Situation Analysis Study, The Population Council, New York. 
Data collected through the inventory instrument provided information on the availability of services, client loads and functional status of the following subsystems through which FP and STD services are provided.

$1 \quad$ Logistics/supplies

2 Facilities/equipment

3 Staffing/training

4 Supervision/management

$5 \quad$ IEC materials and activities

6 Record keeping and reporting.

Data collected through the staff interview, observation guide/exit interview and the $\mathrm{MCH}$ client interview are used to describe the quality of service provided. The service quality indicators have been developed to follow the quality of care framework first developed by Bruce, Jain and others at The Population Council ${ }^{9}$.' These indicators ${ }^{10}$ are grouped according to a number of key elements identified in the Bruce-Jain framework, namely:

1 Interpersonal relations

2 Choice of method

3 Understanding clients' needs

$4 \quad$ Information given to clients

5 Technical competence

6 Mechanisms to ensure continuity of care

One innovative aspect of this study was that it was the first time data were collected through a SA study to measure specifically the quality of service provided relating to STD management and AIDS prevention activities. These data were collected through the same instruments by developing new items for each instrument that collected data pertaining specifically to STD/AIDS. The prevention indicators developed by WHO to monitor and evaluate National AIDS Control Programs were used to develop most of the new items in the instruments ${ }^{11}$." The development of these items was undertaken in collaboration with staff from the Botswana $\mathrm{MOH}$, Ministry of Local Government, USAID and Centers for Disease Control (CDC) in Atlanta, USA.

Training of the research teams required approximately twenty-one days and was held immediately prior to the fieldwork. The training included reviewing the instruments, role playing

\footnotetext{
9 Bruce, Judith, (1 990), "Fundamental Elements of the Quality of Care: A Simple Framework," Studies in Family Planning 21:2; S. Kumar, A. Jain \& J. Bruce, (1 989), Assessing the Quality of Family Planning Services in Developing Countries. Programs Division Working Papers No. 2, The Population Council, New York.

10 A set of quality of care indicators for FP services that can be measured using data from the SA studies have already been developed. See Askew,I.,etal,(1994),"Assessing the quality of care in Nigeria'. Studies in Family Planning, September.

11 Mertens T., Carael M., Sato P., et al, (1 994), 'Prevention Indicators for evaluating of National AIDS Control programs.' AIDS, 8:13 59-1369.
} 
and practical experience. Technical assistance in this training was provided directly to the $\mathrm{MOH}$ by the Africa OR/TA H Project and the Center for African Family Studies (CAFS).

\section{Fieldwork}

Fieldwork lasted for 25 working days spread over six weeks. Each of the nine research teams collected data from one health facility per day, thereby visiting approximately 25 health facilities during the six-week period. Each team consisted of three members: two nurse-midwives with FP service delivery experience and one interviewer experienced in social science research. One team member was assigned as team leader. The team leader was responsible for arranging the travel logistics and financial administration, ensuring adequate quality checks on the data collected, and general troubleshooting for the team. Although each team was autonomous, their activities were coordinated by the principal investigator who visited each team at least once in the field to collect completed data collection forms and provide necessary support.

Observations of client-provider interactions were undertaken by the nursemidwives and the FP and $\mathrm{MCH}$ client interviews were done by the interviewers. The second nurse-midwife and the team leader administered the inventory and staff interviews, normally in the afternoon when the health facilitv was less busy.

\section{Data processing and analysis}

The team leader undertook initial checking of all data collection forms in the field. Data forms were then forwarded to the MOH, Family Health Division office for further checking and entry into the computer. EPI Info was used for data entry, data editing and basic tabulation. The principal investigator spent two weeks in Nairobi, Kenya working with Population Council staff on further analysis of the data and preparation of the report.

\section{Dissemination and use of information}

The most important component of the dissemination and utilization of the research findings was accomplished through the full involvement of program managers (from the MCH/FP Unit, Health Research Unit, AIDS/STD Unit), other interested MOH staff and USAID staff in the planning, implementation, and analysis of the research data. Their participation in the planning and data interpretation workshops ensured their full control and consensus over the types of data collected and how the results were analyzed and interpreted.

\section{Data interpretation workshop}

Potential users of the results from the study were invited for a two-day Data

Interpretation Workshop in Gaborone (5-6 October 1995) to discuss the findings from the 
preliminary analysis, suggest interpretations to these findings, suggest further analysis and formulate a dissemination plan for the study findings. The workshop was attended by program managers, donors and some service providers. Basic frequency distributions and graphic presentations of the study findings were prepared and presented for discussion at the workshop. During this workshop, the participants identified the substantive findings from the study, made suggestions for further data analysis and programmatic recommendations. A format for presenting the key findings in a report was discussed and agreed upon by the participants.

\section{National dissemination workshop}

A preliminary report which included both the substantive findings and the suggested programmatic recommendations was prepared by Family Health Division staff and Africa OR/TA II Project staff following the data interpretation workshop and a national seminar held in March 1996 in Gaborone. Representatives from national and district levels were invited to discuss the preliminary report and make final recommendations. These recommendations are included in this final report of the study findings.

\section{Principal findings and conclusions}

\section{Study population and characteristics}

A total of 451 staff providing $\mathrm{MCH} / \mathrm{FP}$ services in the facilities were interviewed. All staff providing $\mathrm{MCH} / \mathrm{FP}$ services on the day the health facility was visited were interviewed except at health facilities with more than five staff members where a maximum of five staff members were interviewed. On average, two staff members were interviewed at each of the health facilities covered by the study. The staff interviewed included: 125 nurse midwives, 151 nurses with no midwifery training, 163 family welfare educators (FWE), one doctor and nurse practitioners. Most of the staff interviewed were of the Christian faith with only I\% stating that they did not have any religious affiliation. Most of the staff were not married at the time of the survey. More than 50 percent were single or cohabiting while I 1\% were widowed, divorced or separated. The majority $(72 \%)$ of the staff were currently using a contraceptive method at the time of this study. More than $50 \%$ of the staff were using the condom. However, $16 \%$ of the staff reported condom use plus another method of contraception at the same time (Table 1). 
Table 1. Characteristics of service providers interviewed

\begin{tabular}{|l|l|c|}
\hline Characteristics & Category & $\begin{array}{c}\text { \% staff } \\
\mathrm{N}=451\end{array}$ \\
\hline \multirow{4}{*}{ Designation } & Nurse Midwives & 28 \\
\cline { 2 - 3 } & Nurses without Midwifery & 33 \\
\cline { 2 - 3 } & FWEs & 36 \\
\cline { 2 - 3 } $\begin{array}{l}\text { Contraceptive } \\
\text { Use }\end{array}$ & Others & 3 \\
\cline { 2 - 3 } & & \\
\cline { 2 - 3 } & Pill & 13 \\
\cline { 2 - 3 } & IUCD & 5 \\
\cline { 2 - 3 } & Condoms alone & 36 \\
\cline { 2 - 3 } & Condoms with another & 16 \\
\cline { 2 - 3 } & method & 10 \\
\cline { 2 - 3 } & Injectable & 5 \\
\cline { 2 - 3 } & Tubal Ligation & 5 \\
\cline { 2 - 3 } & Other & 28 \\
\hline \multirow{5}{*}{5} & None & \multicolumn{2}{|c|}{} \\
\hline & \multicolumn{2}{|c|}{} \\
\hline
\end{tabular}

12 The percentages do not add to $100 \%$ because some of the staff who were using the pill, IUCD, and injectable were also using the condom and have been counted twice. 
Exit interviews were conducted for $724 \mathrm{MCH}$ clients at 175 facilities and $386 \mathrm{FP}$ clients at 144 facilities during the study. Some facilities included in the study were not providing $\mathrm{MCH}$ and/or FP services on the day of the survey of the interaction between the service providers and FP clients were carried out for 406 clients. Conducting exit interviews for all the clients whose interactions had been observed was not possible as some of them refused to give consent for the interviews. Table 2 shows some selected characteristics of the clients interviewed. Only $25 \%$ of the clients were currently in a marital union and another $2 \%$ were divorced, separated or widowed. The rest were either single or cohabited with no formalized relationship. The pattern of marital relationships found by this study is different from that reported in most African countries where most women are usually married. However, these findings are similar to those reported in the Botswana Family Health Survey II of 1988. More than 400/o of the MCH and FP clients had attained educational levels beyond primary school. Only $11 \%$ and $9 \%$ of the $\mathrm{MCH}$ and FP clients, respectively, had no education at all. Although most of the clients had gone to school a significant proportion, $37 \%$ and $39 \%$ of the $\mathrm{MCH}$ and FP clients, respectively, could only read and understand Sestwana. The inability of these clients to read and understand English easily has to be taken into account when developing IEC materials. There was no difference in the mean age of the $\mathrm{MCH}$ and FP clients. The $\mathrm{MCH}$ clients reported a higher number of living children (mean 3) compared to the FP clients (mean 2).

Table 2. Characteristics of the MCH and FP clients interviewed

\begin{tabular}{|l|l|c|c|}
\hline Characteristics & Category & $\begin{array}{l}\text { \% FP } \\
\text { Clients } \\
\text { N= 386 }\end{array}$ & $\begin{array}{l}\text { \%MCH } \\
\text { Clients } \\
\text { N= 724 }\end{array}$ \\
\hline \multirow{5}{*}{ Education } & None & 9 & 11 \\
\cline { 2 - 4 } & Adult Education & 4 & 4 \\
\cline { 2 - 4 } & Lower Primary & 9 & 10 \\
\cline { 2 - 4 } & Upper Primary & 35 & 36 \\
\cline { 2 - 4 } & Lower secondary & 31 & 36 \\
\cline { 2 - 4 } & Upper Secondary + & 12 & 12 \\
\hline Marital Status & Married & 25 & 24 \\
\cline { 2 - 4 } & $\begin{array}{l}\text { Cohabiting/Living } \\
\text { together }\end{array}$ & 29 & 33 \\
\cline { 2 - 4 } & Single & 44 & 41 \\
\cline { 2 - 4 } & $\begin{array}{l}\text { Divorced/Widowed/ } \\
\text { Separated }\end{array}$ & 2 & 3 \\
\hline \multirow{2}{*}{} & \multicolumn{2}{|}{} \\
\hline
\end{tabular}

${ }^{6} 13$ See Botswana Family Health Survey 


\section{Functional status of subsystems at health facilities}

Infrastructure: Figure 2 shows that most of the facilities surveyed had the basic infrastructure in place. More than $80 \%$ had piped water, a waiting room and a working toilet for clients. However, $42 \%$ of health posts did not have a designated waiting room/area. It was also found that $25 \%$ of the waiting areas/rooms were not protected from sun and rain. The absence of waiting areas/rooms or lack of protection from sun and rain at health facilities will affect the conducting of group IEC activities since most of the facilities depend on these areas for these activities.

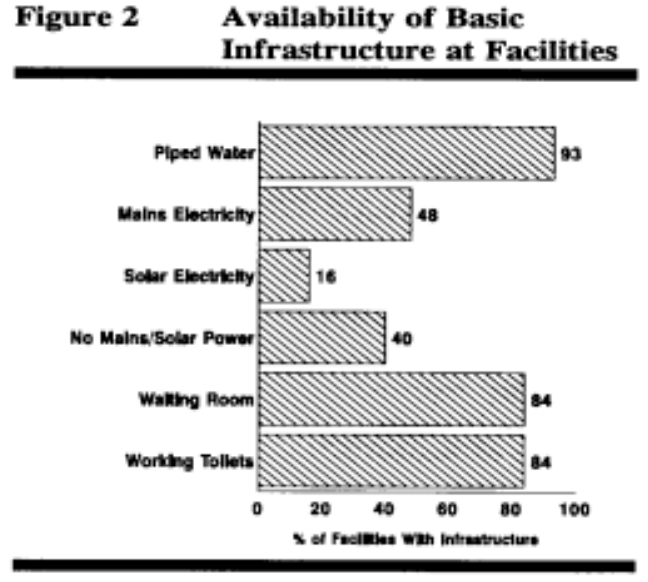

The data in Figure 2 also show that a significant number (40\%) of the facilities did not have functioning mains or solar electricity on the day the facility was visited. Electricity was lacking at $59 \%$ of the facilities in the rural areas compared to only $5 \%$ in the urban and $25 \%$ in semi-urban areas. Most of the health posts $(69 \%)$ did not have any form of electricity. The majority of the hospitals $(95 \%)$ and clinics (66\%) had access to electricity. Electricity is a major source of energy for lighting, sterilization of equipment and storage of perishable supplies like vaccines. Therefore, the lack of electricity in a health facility may compromise the quality of care provided and lead to wastage of perishable supplies.

Equipment and supplies: Basic equipment necessary for the provision of MCH/FP and STI services, for example, adult weighing scales, disposable gloves, blood pressure machines, specula and sterilizing equipment, were available in most of the facilities. However, Figure 3 shows that $59 \%$ did not have an examination lamp or a working torch to facilitate pelvic and other examinations. Equipment necessary for IUCD insertion was lacking in a significant number of facilities. Adequate supplies of vaginal speculum were missing at $15 \%$ of the facilities. Although the majority (more than $85 \%$ ) of the facilities provide basic immunization services, only $50 \%$
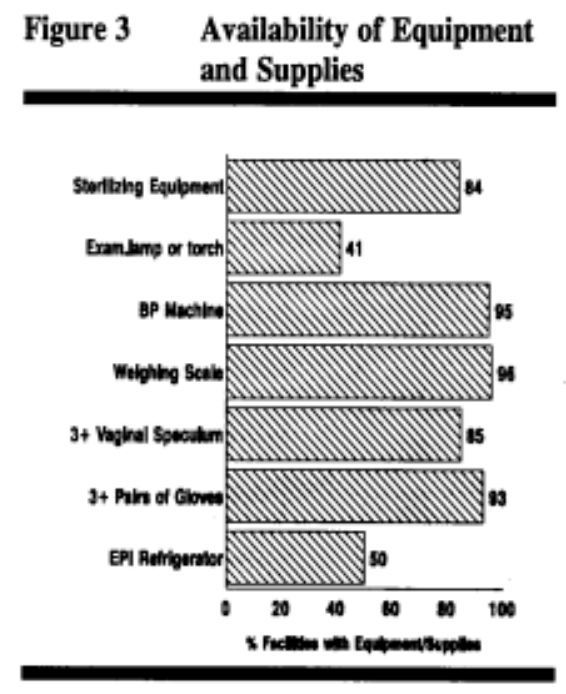
had a working EPI refrigerator. The rest of the facilities had to rely on ordinary frigerators to store vaccines.

This can be associated with problems of maintaining the cold chain and may lead to use of non-viable vaccines and wastage. 
Laboratory and screening facilities for STIs and HIV/AIDS: All clients receiving antenatal care services from the health facilities are supposed to be screened for syphilis infection. Screening for cancer of the cervix is one of the components of the family planning program in Botswana. Both these services require access to some basic laboratory facilities either at all the health facilities or referral facilities that the clients would reach easily. Given that the sensitivity and specificity of the Syndromic Approach to diagnose ST1s are very low, especially if used in low risk populations, the need for laboratory back-up services will continue to exist. This study found that most of the facilities lacked easy access to basic laboratory services.

Table 3 shows that the VDRL test for syphilis was available at 16\% of the facilities while HIV (ELISA) and Pap Smear tests were available at less than 5\% of the facilities. Gonorrhea test (Gram Stain) was available at $10 \%$ of the facilities. These tests were more likely to be available at the hospitals than at any other facilities. However, the HIV (ELISA) test was available at less than $50 \%$ of the hospitals. Most of the facilities indicated that they refer the clients or send specimens to other facilities where these tests are available. Results from tests that are carried out at the referral laboratory are rarely available on the same day that the specimen or client is referred. For example, it takes an average of 5 and 4 days to obtain VDRL and Gram Stain test results, respectively. The results for MV test and Pap Smear take on average 18 and I I days, respectively, to reach the referring health facility. This data shows that clients have to make at least two trips to the health facility; first to have the specimens taken and again to get their test results and receive treatment where necessary. There are simple and more cost-effective methods available on the market for most of the ST1s which do not require sophisticated laboratory facilities and provide results immediately. There is a need to consider adopting some of these technologies as they will improve the quality of services provided and reduce the number of visits clients have to make to the clinics.

Table 3. Diagnostic and screening facilities for STD/HIV/AIDS available in a health facility.

\begin{tabular}{|l|c|l|l|l|c|}
\hline Laboratory test & \multicolumn{5}{|l|}{ Percent of facilities where tests are available } \\
\hline & $\begin{array}{l}\text { Hospita } \\
\text { ls } \\
\mathbf{N = 2 0}\end{array}$ & $\begin{array}{l}\text { Clinics } \\
\text { with } \\
\text { Maternity } \\
\mathbf{N = 4 7}\end{array}$ & $\begin{array}{l}\text { Clinics } \\
\text { Without } \\
\text { Maternity } \\
\mathbf{N = 4 5}\end{array}$ & $\begin{array}{l}\text { Health } \\
\text { Posts } \\
\mathbf{N = 4 5}\end{array}$ & $\begin{array}{l}\text { Total } \\
\mathbf{N = 1 8 6}\end{array}$ \\
\hline Syphilis: VDRL & 95 & 9 & 8 & 2 & 16 \\
\hline Gonorrhea: Grain stain & 75 & 2 & 4 & 0 & 10 \\
\hline HIV:ELISA & 45 & 2 & 1 & 0 & 3 \\
\hline $\begin{array}{l}\text { Cervical Cancer: Pap } \\
\text { Smear }\end{array}$ & 15 & 2 & 4 & 0 & 4 \\
\hline Pregnancy Test & 70 & 53 & 41 & 13 & 41 \\
\hline
\end{tabular}


IEC Materials and activities: Except for wall posters, Information, Education and Communication materials were generally lacking in most facilities. More than $60 \%$ of the facilities had at least one wall poster on family planning, child welfare and HIV/AIDS. Although flip charts are an essential teaching aid during IEC activities, most of the facilities surveyed did not have a flip chart for family planning (700/o), STI (85\%), HIV/AIDS (86\%), ANC (81\%) and child welfare (68\%). Although the national STD/AIDS control programme has produced many IEC materials on HIV/AIDS, this study found that many facilities lacked pamphlets, brochures and wall posters on the subject. Brochures and pamphlets for family planning and HIV/AIDS were available in 58\% and $60 \%$ of the facilities, respectively (Figure

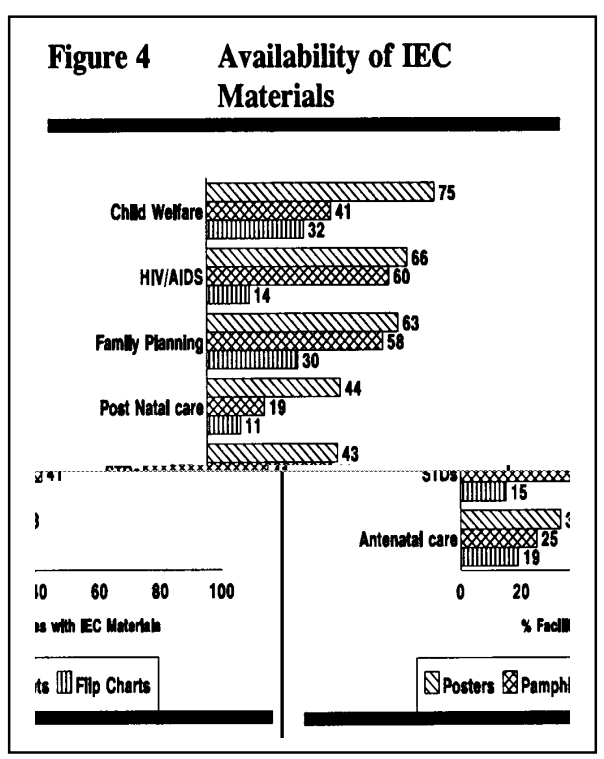
4).

The data also show that IEC materials on postnatal care were available in few facilities. Only I $1 \%$ and $19 \%$ of facilities had flip charts and brochures, respectively, on postnatal care.

During the national dissemination workshop the participants were informed that the Health Education Unit at the Family Health Division and the national STD/AIDS control Unit have produced many IEC materials which were awaiting collection by the District Health Teams for distribution to the health facilities in their districts. Therefore, the absence of IEC materials in the health facilities may be an indication of the logistics problems faced in distributing these materials and monitoring of IEC activities rather than the availability of the materials themselves. Besides the distribution problems, most of the IEC materials available are in the English language, yet many clients can only read and understand Setswana. 
As part of their routine IEC activities, the staff at each health facility are expected to hold a group "health talk' for $\mathrm{MCH} / \mathrm{FP}$ clients on each clinic day. Group health talks were held at only $27(14 \%)$ of the facilities on the day of the survey. Family planning, STI and HIV/AIDS related topics were covered in less than $20 \%$ of the group "health talks" observed (Figure 5). These findings show that service providers are not taking advantage of this forum to inform clients about other health issues. Participants at the national workshop to disseminate the findings from this study noted that staff have to deal with large client loads making it nearly impossible to provide individual IIEC and counseling to clients.

The participants suggested that use of group IEC and counseling for the clients may be a more practical solution.

Contraceptive supplies and logistics: The combined pill, condoms and Depo Provera were provided at more than $90 \%$ of the facilities surveyed while the IUCD was available at $73 \%$ of these facilities (Table 4 ). Tubal litigation was provided by only eight of the 20 hospitals visited as part of the study. During this study, clients were asked to state if they wanted to have any more children in the future. A large number ( $48 \%$ of the $\mathrm{MCH}$ and $38 \%$ of the FP clients) said that they would not like to have any more children. In the Botswana Family Health Survey II it was also found that $33 \%$ of the women did not want to have any more children. The findings from this study suggest that there is a large unmet need for permanent methods in Botswana yet most of the facilities do not provide these methods.

\section{Table 4 Availability of contraceptive commodities and supplies ${ }^{14}$,}

\begin{tabular}{|l|c|c|c|c|}
\hline $\begin{array}{l}\text { Types Of } \\
\text { Contraceptive }\end{array}$ & $\begin{array}{l}\text { Percent } \\
\text { providing } \\
\text { method } \\
\text { N= 186 }\end{array}$ & $\begin{array}{l}\text { Percent without } \\
\text { supplies of day } \\
\text { of visit }\end{array}$ & $\begin{array}{l}\text { Percent with } \\
\text { expired } \\
\text { quantity on } \\
\text { day of visit }\end{array}$ & $\begin{array}{l}\text { Percent } \\
\text { reporting } \\
\text { stockout in } \\
\text { previous six } \\
\text { months }\end{array}$ \\
\hline Combined Pill & 96 & 4 & 6 & 12 \\
\hline $\begin{array}{l}\text { Progesterone } \\
\text { only Pill }\end{array}$ & 95 & 8 & 12 & 10 \\
\hline Condom & 93 & 13 & 3 & 23 \\
\hline IUCD & 73 & 13 & 13 & 9 \\
\hline Depo Provera & 94 & 6 & 8 & 11 \\
\hline
\end{tabular}

Use of spermicides has been shown in a number of studies in the region to reduce the transmission of STIs and HIV infection in addition to their contraceptive 
effects ${ }^{15}$ In the recent years, Botswana has experienced a rise in the prevalence of STIs and HIV infection. That few facilities (fewer than 10\%) are providing spermicide may be due to the fact that policymakers and service providers are not aware of the above information about the value of these agents for protecting women against STDs.

On the day of the survey, $13 \%$ of the facilities providing condoms and IUCD's did not have supplies of these commodities. More than $5 \%$ of the facilities had expired stocks of pills, IUCD's and Depo-Provera in their stores. In the six months before this study, $23 \%$ of the facilities had experienced at least one stockout of condoms. These data show that staff do not adhere to the policy requiring each health facility to have stocks of unexpired commodities to last two months at any given time. Frequent stockouts and the existence of expired drugs are an indication of the capabilities of staff at these facilities to manage their contraceptive supplies. However,

shortages at the central stores and/or delays in responding to the requests from the clinics could also be responsible for the stockout and lack of supplies at the health facilities.

Management and supervision: Supervision of services at the health facilities is carried out by various cadres of staff covering different aspects of the services. The District Medical Officers (DMO) appear to make more supervisory visits than other categories of staff. More $\mathrm{dm} 70 \%$ of the facilities were visited at least once by the DMO in the six months preceding this study. The DMOs are expected to routinely visit the facilities to provide clinical services. This may explain the high number of facilities reporting a supervisory visit by a DMO. It is possible that the DMOs combine their routine clinics visits

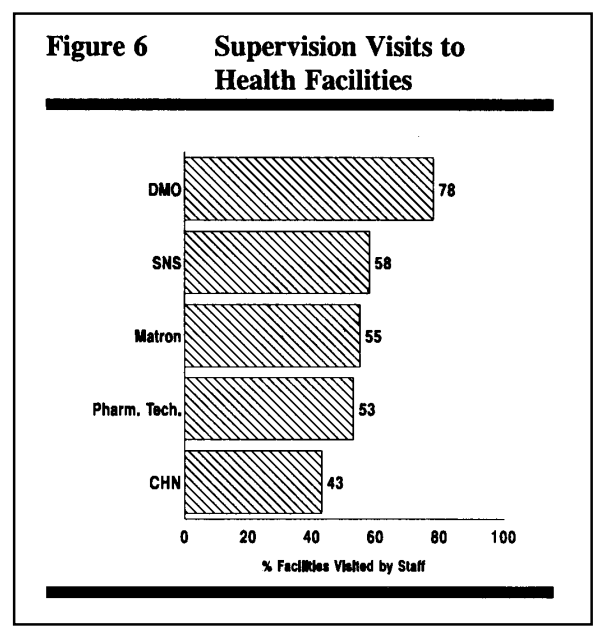
with supervision activities or the service providers mistake these clinic visits to be for supervision.

The rest of the categories of staff expected to undertake supervision visited less than $60 \%$ of the facilities over the same period (Figure 6). Overall, more than $90 \%$ of the facilities were visited at least once for supervision purposes by at least one of the staff expected to make supervision visits in the six months prior to this study. The

\footnotetext{
$1_{4}$ he percentages of facilities without supplies, with expired supplies and stockout experiences are calculated for only those facilities that provide the contraceptive method.

15 Fox, J.L., Williamson, E.N., Cates, W., et al., (1 995), 'Improving Reproductive Health:Integrating TD and contraceptive Services, JAMWA. 50:129-136.
} 
proportion of facilities visited for supervision were similar for urban, rural and semiurban setting.

The persons in charge of the health facilities were asked to state what the supervisors did during the supervision visits to the facilities. Data from these interviews show that the supervisors asked about service problems in the majority and reviewed records at half the facilities during their supervision visits (Figure 7). Other activities performed during the supervision visits included observation of the delivery of services (43\%) and making suggestions for improvements (38\%). At only $13 \%$ of facilities where a supervision visit was made did staff spontaneously report that supervisors offered praise for good work. These data show that there is no standardized approach to supervision and monitoring of $\mathrm{MCH} / \mathrm{FP}$ services.

The activities undertaken by the supervisors depend on the individuals' interests and understanding of what they are expected to do. Recall and other forms of biases may also influence the information obtained through interviewing clinic staff about events that occurred six months ago. This makes it difficult to compare the performance of the different facilities and programs supervised by different individuals. These problems could be overcome through the development and use of standardized supervision checklists and manuals.

Figure 7 also shows that the supervisor only checked on the services they are responsible for in $37 \%$ of the facilities where supervision visits took place. This may be the result of the manner in which the services themselves are structured and the way the supervisors' responsibilities were developed and presented to them. The policy of the Botswana government is to provide primary health care services using an integrated approach. If the idea of integration is to succeed at the health facility level, there is need for the process to be seen to work at higher levels. The failure of the supervisors to use the integrated approach during their supervision visits sends a contradictory message about integration to the service providers. 
Record keeping. More than $90 \%$ of all facilities indicated that they keep records of family planning commodities, drugs for treatment of STDs and vaccines. There was no major difference on availability of records between the different types of health facilities surveyed. However, it was found that the quality of record maintenance was not satisfactory in many facilities. More than $30 \%$ of the clinics without maternity and of health posts had stockbooks/inventories that were not well Maintained (Figure 8 ) $^{16}$ Overall, facilities in the urban areas tended to have better

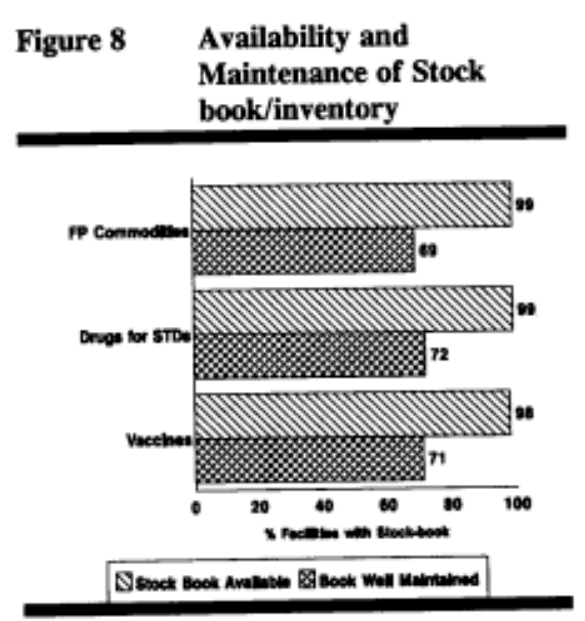
maintained stock books/inventories compared to those in semi-urban and rural areas.

Well-kept records are useful in monitoring commodity flows and services provided. Poorly maintained records may explain why some facilities did not have supplies of commodities and/or had expired commodities which the staff were not aware of.

All the facilities surveyed prepare services statistics reports which they submit to a supervisor or higher authority monthly. The study did not find out whether feedback is regularly sent back to the facilities and if so what mechanisms are used.

Storage facility and conditions: Although most of the facilities had adequate storage facilities, a significant number were not storing their commodities according to expiry dates. It is recommended that supplies and commodities be stored using the "first expiry first out" concept as it facilitates the use of supplies and commodities in the order of their expiration dates.

\section{Service provider preparedness to provide MCH/FP and STI/HIV/AIDS services.}

To learn about staff preparedness to provide MCH/FP and STI/HIV/AIDS services, interviews were conducted with 451 staff providing these services in the facilities included in this study. The staff were interviewed about their training background, experience with providing $\mathrm{MCH} / \mathrm{FP}$ and STI/HIV/AIDS services, history taking and clinical assessment skills and practices.

${ }_{6}^{16}$ A stockbook/inventory was considered to be well maintained if it was found to be up-to-date and legible and complete for the reformation that was expected to be recorded in it. 
Availability of staff.. At nearly all of the facilities, there are no service providers allocated to work only in the MCH/FP section on a full-time basis. Staff are allocated responsibilities on a weekly basis in any of the sections of the health facility. This study did not establish the basis on which staff are allocated to the various sections. Figure 9 shows that in all the facilities visited, only $4 \%$ of them had medical doctors on duty in the MCH/FP section. Less than $50 \%$ of the facilities had a staff nurse midwife or enrolled nurse midwife on duty in the $\mathrm{MCH} / \mathrm{FP}$ section on the day of the survey. These results suggest that $\mathrm{MCH} / \mathrm{FP}$ services were being provided by staff whose training did

Figure 9 Categories of Staff Providing MCH/FP Services at Health Facilities

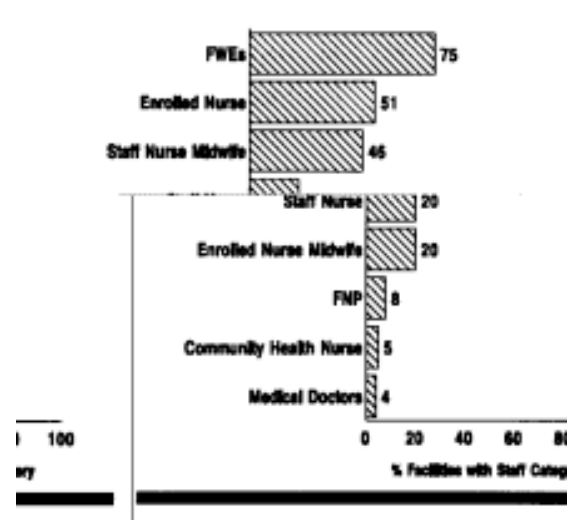
not adequately cover antenatal, postnatal and family planning services.

The three year training for enrolled nurses only provides an introduction to family planning and $\mathrm{MCH}$ services. The enrolled nurses have to undergo a post graduate training in family planning and $\mathrm{MCH}$ services before they are officially recognized as capable of providing these services.

Staff experience: Using a checklist, staff were asked to indicate which services they provided to clients at the health facilities. More than $95 \%$ of the staff said that they provide family planning and child welfare services at the facilities in the study. However, more than $30 \%$ of the staff interviewed were not providing STI/HIV/AIDS, antenatal, maternity and postnatal services (Figure 10). Enrolled nurses (whose basic training does not include midwifery) and family welfare educators (FWES) account for $61 \%$ of all the staff

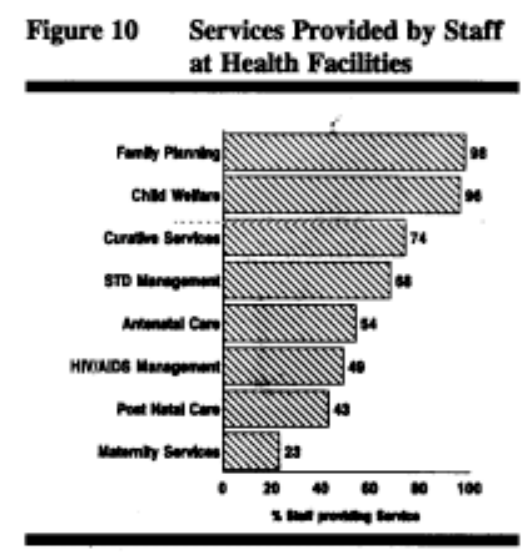
interviewed.

The majority of these enrolled nurses, $72 \%, 92 \%$ and $89 \%$, said that they do not provide antenatal, maternity and postnatal services, respectively, while fewer than $35 \%$ of the FWEs said that they provide STI and HIV/AIDS services even when counseling and IEC activities are included. The large number of nurse midwives and FWEs not providing these services may explain the findings shown in Figure 10. 
More than $85 \%$ of the staff interviewed had provided pills and condoms to clients in the three months preceding the study. The majority $(59 \%)$ of the staff had provided injectable contraceptives but only $29 \%$ reported having inserted an IUCD over the same period. A larger number $(61 \%)$ of the staff had referred clients for an IUCD to another facility or within the same facility to another service provider (Figure I 1). Insertion and removal of IUCDs require special training of the service providers. Only $39(9 \%)$ of the service providers said that

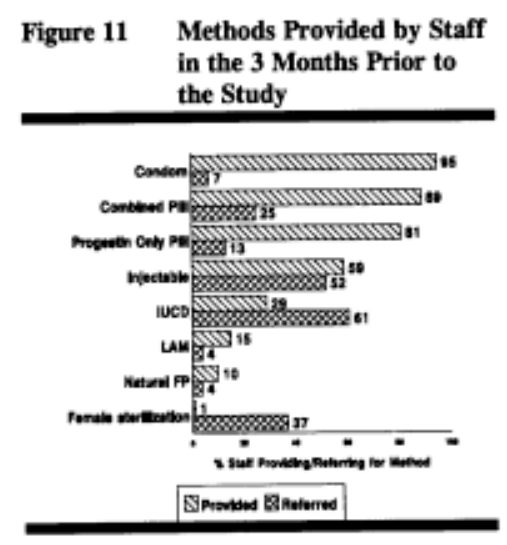
they had attended a course on IUCD insertion and removal.

This number is much lower than the 131(29\%) of staff who said that they had inserted and/or removed an IUCD in the three months preceding this study.

This finding suggests that staff who have not attended a formal course on IUCD insertion and removal are providing these services. The only possible explanation is that they have received on-the-job training from their colleagues but did not consider this as training when responding to the question on training in IUCD insertion and removal. The majority $29(74 \%)$ of the service providers trained in IUCD insertion and removal had provided IUCDs to clients in the three months preceding this study. Lack of training in IUCD techniques and equipment or supplies necessary for IUCD insertion in some facilities may explain the low number of staff providing the method.

Less than $20 \%$ of the staff had taught clients how to use natural methods and breast-feeding for family planning. Surgical methods are not common in the Botswana family planning program. However, $37 \%$ of staff had referred a client for female sterilization in the three months preceding the study. Norplant@ is still at a pilot stage and so far there are only two pilot areas and both are found in the capital. During this study, $15 \%$ of the staff stated that they had referred a client for Norplant@. The practices of staff reflect the distribution of methods available in the program. 
Staff training. Most staff have received training in all important fields of $\mathrm{MCH}$ and family planning (Figure 12). More than 90\% were trained in child welfare and family planning while antenatal care and STI management were covered in the basic training of $660 \%$ of the staff interviewed. Only $23 \%$ and $28 \%$, of the providers covered HIV/AIDS management and midwifery, respectively, in the basic training. HIV/AIDS is a new disease and it is unlikely that it would have been covered in the basic training of most staff.

The majority (more than $80 \%$ ) of the stag had attended a refresher course or a post basic course. More than half of the providers had attended a refresher course where topics on STD and HIV/AIDS management were covered.

The lowest and most frequent point of first contact in the health care system in Botswana is the health post which is manned primarily by the FWE. The FWEs' primary responsibility is that of educating and motivating families and communities about health issues., However, the FWEs are the ones that make primary contact with the clients in primary health care structure and are also responsible for referring clients to higher levels of health personnel. The FWEs are also expected to counsel men and women about family

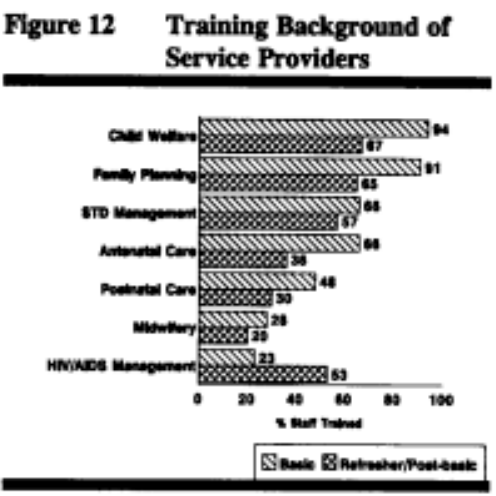
planning to facilitate informed choice.

They screen clients who wish to use the contraceptive pill and initiate supplies both at the clinic and in the community. ${ }^{17}$ Often they are the only service providers available at the Health Posts working under supervision from the nearest clinics.

The basic training for the FWEs focuses on child welfare and family planning services. Figure 13 shows that only $8 \%$ of the FWEs covered HIV/AIDS and maternity services during their basic training. Antenatal care and STI management were covered for less than half of the FWEs. The adoption of the integrated approach in providing $\mathrm{MCH} / \mathrm{FP}$ and STI/HIV/AIDS services will of necessity broaden the responsibilities of the FWEs. Based on the broader responsibilities that the FWEs will have, there is need for all of them to be trained in other MCH and STI services. For those already in the field, refresher courses covering STI/HIV/AIDS, postnatal and antenatal services will be required ${ }^{9}$

\footnotetext{
${ }_{7} 7$ Botswana Primary Health Care Evaluation: Final Report (1 984). Health Education Unit, Ministry of Health, Gaborone Botswana
} 
The majority $(69 \%)$ of the staff have attended a training (basic, post-basic post-refresher) that included topics on STI/HIV/AIDS. The staff who had attended a course covering STI/HIV/AIDS related topics were asked to name the topics covered in the courses (Figure 14). Although the syndromic approach to diagnosis and treatment of STI was introduced in 1992 , less than $50 \%$ of the staff trained in STI/HIV/AIDS management have attended courses that included topics on the syndrornic approach, risk assessment and counseling for these conditions.

Staff skills, practices and competence: Staff who said that they had provided the pill, IUCD, injectable and Norplaht@ were asked to name the clinical procedures they carry out for new clients who choose to use these methods. The proportion of service providers saying that they perform a blood pressure check before offering some methods ranged from 59\% for Norplant@ to 91\% for the pill (Figure 15). Only 35\% of the staff said that they perform pelvic examination before providing the pill to a new client and half said that they perform pelvic examinations before offering the IUCD. According to the available $\mathrm{MCH} / \mathrm{FP}$ service procedure manual all new clients receiving the pill,
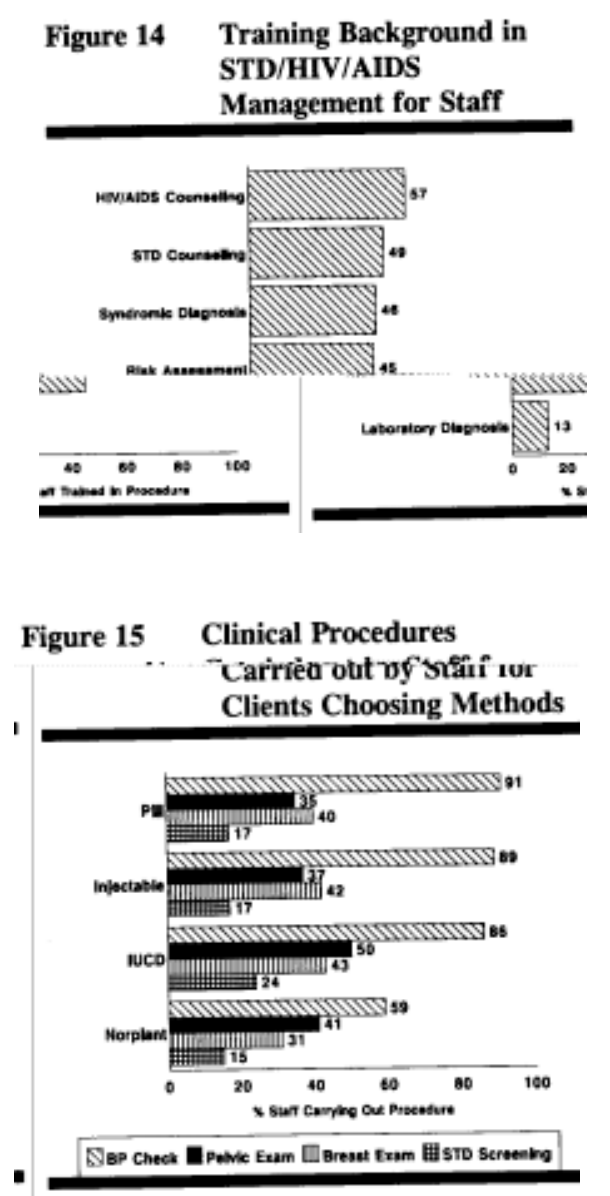

IUCD and injectable should have a pelvic, breast, blood pressure and general physical examination. Although a speculum is used during IUCD insertion does not necessarily mean that a pelvic examination has been performed. A pelvic examination involves more than just inserting a speculum. It includes inspection of the external genitalia vaginal walls and cervix in addition to a digital palpation of the internal genitalia. These data suggest that the service providers insert IUCDs without proper pelvic examination.

Screening of sexually transmitted diseases was not a common practice among these service providers. The Botswana Family Planning General Policy Guidelines and Standards manual ${ }^{18}$ lists STIs and HIV/AIDS as absolute contraindications to the use of IUCDs yet less than $25 \%$ of the ${ }^{10}$

18 Maternal and Child Health/Family Planning Department of Primary Health Care Unit, Ministry of Health, (1 987), Botswana Family Planning General Policy Guidelines and Service Standards, Ministry of Health, Gaborone. (Also see revised draft, 1994) 
service providers said that they perform STD screening of clients before providing any of the methods including IUCDS. Less than $50 \%$ of the staff said that they carry out breast examination for new family planning clients seeking to use the pill, injectable, IUCD or Norpiant@. These findings show that the service providers are not following the policy guidelines and service standards of the family planning program.

The Subcommittee on STI/HIV of The Evaluation Project (funded by the USAID) listed some key issues that should be considered during history taking for clients with symptoms suggesting STIs. ${ }^{19}$ This fist includes asking about symptoms of $\mathrm{STI} / \mathrm{HIV} / \mathrm{AIDS}$ in the partner, age of client marital status and the presence of new sex partners in the previous four weeks and three months. These indicators greatly enhance the sensitivity and specificity of the syndromic approach in diagnosing ST1s. In 1992, the MOH through the National AIDS Control Programme published a manual for health workers on the management of STIs. ${ }^{20}$ This manual emphasizes the use of the syndromic approach to STI management and outlines topics that must be covered during history taking. The topics outfitted in outlined in this manual are the same ones fisted by The Evaluation Project. The $\mathrm{MOH}$ manual is the main reference material used during the training of service providers and issued to them for use as a reference manual during their day-to-day activities.

Staff participating in this study were asked to list the questions that they ask clients presenting with a vaginal or urethral discharge to decide the possible causes of the discharge. Their responses were then compared to the fist recommended in the $\mathrm{MOH}$ manual. Figure 16 shows that most of the staff do not ask clients about their number of sex partners, marital status and history of symptoms in the partner. This denies the staff the information that would have helped them in classifying women into the appropriate syndromes, beginning the

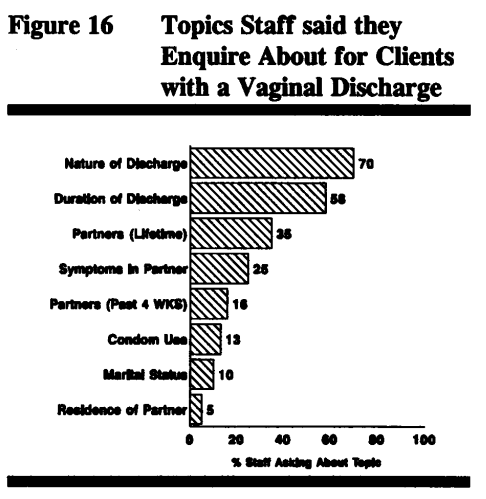
appropriate therapy and advising on behavioral change.

The omission of questions on number of sex partners and history of symptoms may be an indication of a low level of knowledge about risk factors for ST1s among the service providers. ${ }^{11}$ 
The service providers were asked to describe what steps they go through when performing a pelvic examination for clients complaining of a vaginal discharge. Figure 17 shows that the different components of the pelvic examination are not carried out by all staff members for clients with a vaginal discharge. The most commonly performed procedure is inspection of the external genitalia which was stated by $55 \%$ of the staff followed by speculum examination (48\%). Only $20 \%$ of the staff

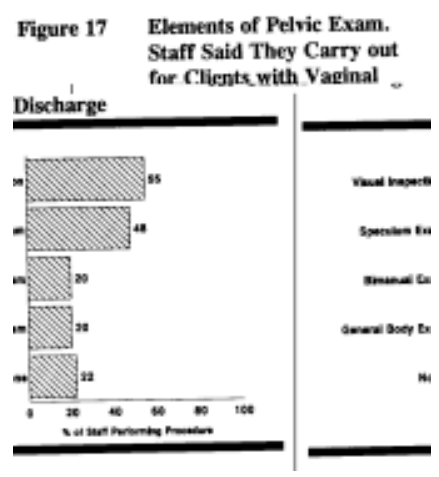
stated that they perform bimanual palpation or digital examination.

Twenty two percent of the staff interviewed said that they do not perform a pelvic examination when assessing clients complaining of a vaginal discharge.

Although hormonal contraceptive methods are very effective in preventing pregnancy, they do not affect the spread of ST1s and HIV infections. Clients who rely only on the hormonal methods are still at risk of being infected or infecting their partners with ST1s and/or HIV. It is therefore recommended that clients using hormonal methods and at risk for ST1s and IUV infection should be advised on using a barrier method in addition. Staff were asked to state the advice that they would give to a repeat client on oral contraceptive pills who is

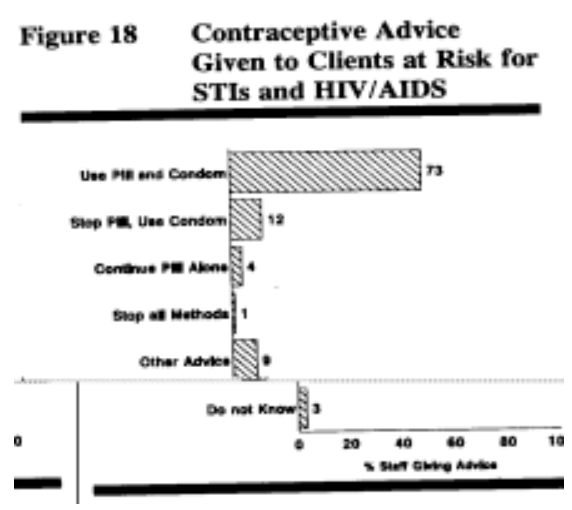

also at increased risk for ST1s and HIV infection. Figure 18 shows that the majority $(73 \%)$ of the staff stated that they would advise the client to use a condom in addition to the oral contraceptive pills. However, it should be noted that $27 \%$ of the staff would give some other advice. The concept of dual contraception is still new an many service providers may not be aware of it. There is a need to update the service providers' knowledge and skills to respond to these new concepts and needs.

Generally, the data from this study identify some areas in which the service providers lack adequate skills. There is a need to improve the service providers' skills as they affect the quality of services provided. At the time of the survey, training of service providers in family planning and STI/HIV/AIDS management had started through the BOTSPA project. The impact of this training on service providers skills will be assessed in the future and the findings from this study will serve as the baseline for these evaluations. 


\section{Accessibility of services.}

Accessibility of services was measured by the convenience of the opening times, closing times, number of days Per week the services are offered, time it takes to get to the service delivery point and mode of transport used to get there. These factors among others determine how easy it is for clients to get the services they require.

Opening times: Figure 19 shows the mean opening time, time staff start to provide services, time last family planning client was seen and the closing time as observed at the study clinics, Although most facilities adhere to the official opening time of 7:30 a. m., the staff start providing services to clients almost an hour later. Most of the facilities stop providing services between 4:30 pm and $5.00 \mathrm{pm}$. which is the official closing time, Based on the official opening and closing times,

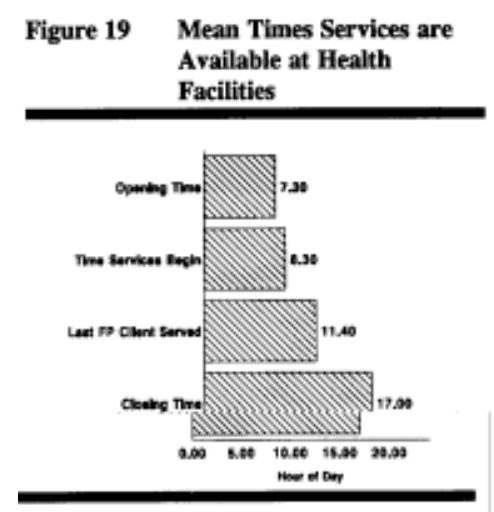

all $\mathrm{MCH} / \mathrm{FP}$ services are available for at least 8 hours per day on average. During the study, it was observed that the last family planning client was served at about 11.40 a.m. at the majority of the facilities visited. It was not clear why this was the case. Is it that clients prefer to come for services in the morning or the staff provide family planning services during the morning hours only? Whatever the case may be, what do those service providers in the family planning section do for the rest of the day?. During the national dissemination workshop, the service providers pointed out that often there is only one service provider at a facility. This service provider spends the morning providing services and the afternoon preparing for the next day. The preparations involve cleaning, parking and sterilizing the equipment, updating records and making requisitions for supplies and equipment.

Fourteen percent of family planning clients reported that they had at sometime been denied services at the facilities during official working hours compared to only $8 \%$ of the $\mathrm{MCH}$ clients. Clients were not asked for the reasons why they had been denied services. This finding should be interpreted with caution since some clients may not be aware of the exact official times when facilities are expected to provide services.

The time it takes for the client to reach a service delivery point is an important determining factor in services utilization. Past studies in reproductive health have shown that clients are ${ }^{21}$ The client or the potential sensitive to distances that they have to travel to get health services. client looks at the opportunity cost of travelling to a facility against the perceived benefits. This study found that $\mathrm{MCH}$ clients had to travel for nearly half an hour to reach a service delivery point while

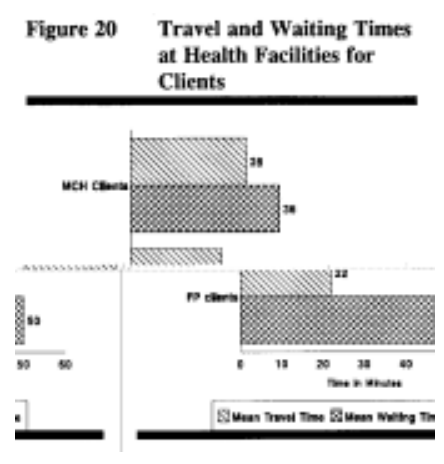


family planning clients took on average 22 minutes. The findings from this study that $\operatorname{most}^{12}$ of the clients (85\%) walked to the health facility and it took them on average 20-30 minutes suggest that most of them live within easy reach to the facilities. On average, $\mathrm{MCH}$ clients had to wait for half an hour after arrival before receiving the services while family planning clients had to wait for 50 minutes (Figure 20). These data suggest that clients receiving family planning services from these health facilities are made to wait longer than those receiving $\mathrm{MCH}$ services before being attended. The reasons for the differences in waiting time were not looked for in this study. Although most of the clients $(88 \%$ and $89 \%$ for MCH and FP clients, respectively) felt that the service hours were convenient for them, some $\mathrm{MCH}$ and FP clients (28\% and $31 \%$, respectively) were not happy with the time they spent at the facilities before receiving service.

Some of the $\mathrm{MCH}$ and family planning clients (1 $9 \%$ and $25 \%$, respectively) said there was another facility nearer to their place of residence other than the one they had visited. Clearly, for these clients, distance was not the only consideration when choosing where to get services.

Availability of services: The policy of the government of Botswana is to provide $\mathrm{MCH} / \mathrm{FP}$ services on a daily basis at all the facilities. According to this policy, clients should obtain any of the $\mathrm{MCH} / \mathrm{FP}$ services during a single visit to a health facility. However, the findings of this study show that this has not been realized in many health facilities. Figure 21 shows that family planning, child welfare and STD services were being offered in more than $90 \%$ of the health facilities on the day of the survey. Less than $70 \%$ of the facilities were offering HIV/AIDS, antenatal and postnatal services on that day.

Availability of signs advertising services: Another important factor in service utilization is clients' awareness of the availability of the services at a health facility. One way of raising this awareness is by using billboards and/or signs conveniently placed outside and within the facilities to announce the services available to clients at the facility. Generally, signs or billboards announcing the availability of FP services are lacking in most health facilities (Figure 22). More than $75 \%$ of all facilities visited did not have any sign notifying

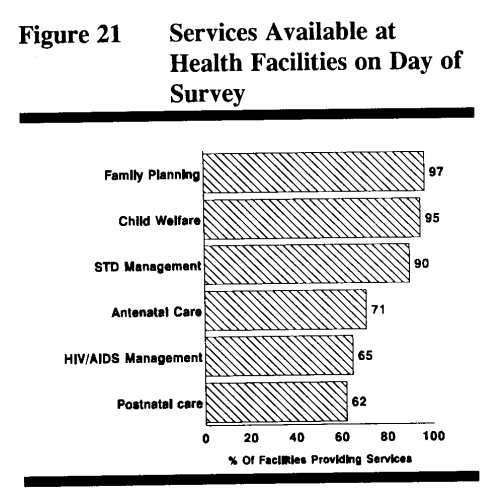
clients of the presence of FP services. One quarter of hospitals, clinics with maternity and clinics without maternity and only $7 \%$ of the health posts

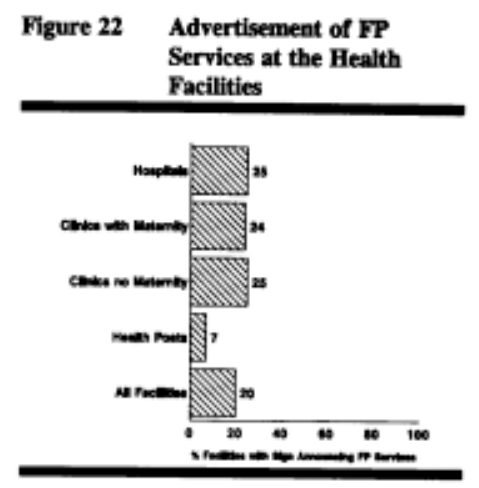

$21 \quad$ Ndhlovu, Lewis (1 995) 'Quality of Care in Family Planning Service Delivery in Kenya: Clients' and Providers' Perspectives.' The Population Council, Nairobi, Kenya 
had any signs notifying clients that FP services are available at the health facilities.

Awareness about other services offered in the health facilities is low. Although STI and HIV/AIDS were available at more than $65 \%$ of the facilities on the day of the survey, fewer than I $0 \%$ of both $\mathrm{MCH}$ and FP clients were aware that they could obtain these services at these health facilities (Figure 23). If clients are not aware that a service is available at the facility, they are less likely to use that service. Clients can be made aware of the availability of services through signs/posters and

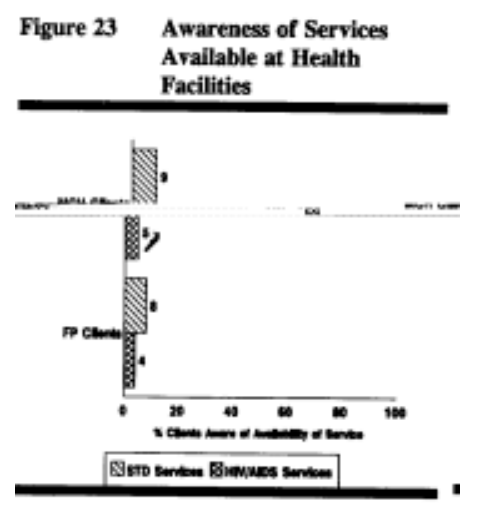
other IEC activities, all of which are generally lacking in most of the facilities.

\section{Quality of care provided}

The assessment of quality of care received by clients seeking family Planning services the health facilities was based on the model developed by J.Bruce. ${ }^{22}$ The model uses six elements to measure quality of care namely: interpersonal relations, provider competence, information given to clients, choice of methods, appropriate constellation of services and mechanisms to continuity. ${ }^{13}$

${ }^{2} 2 \quad$ See J. Bruce et al., Op. Cit 


\section{a) Interpersonal relations}

The perception of the service provider's attitudes by the clients is very important for continued use of the facility and the services ${ }^{23}$ The vast majority $(93 \%)$ of the family planning clients said that they were received and greeted by the service provider in a friendly manner. Generally, clients were happy about the visit to the health facility (Figure 24). More than $90 \%$ of both the $\mathrm{MCH}$ and family planning clients said that they were satisfied with the overall visit and the service provider's explanation of issues that were of concern to them $(87 \%$ and

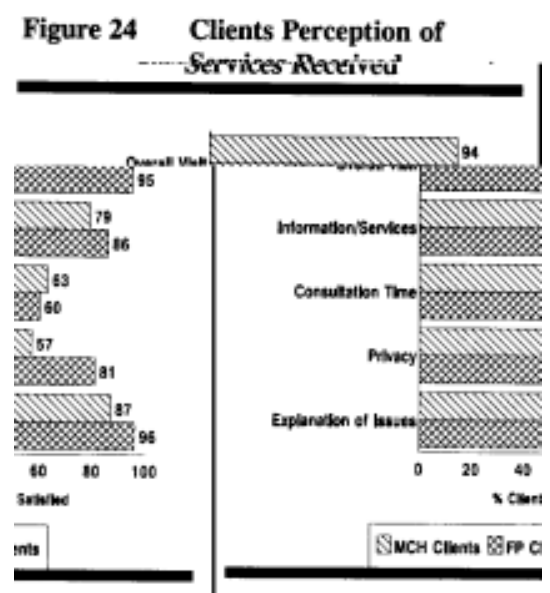

$96 \%$ for $\mathrm{MCH}$ and FP clients, respectively). Privacy during consultation is very important when dealing with sensitive health issues like family planning and STI/HIV/AIDS. It was interesting that more family planning clients $(81 \%)$ than $\mathrm{MCH}$ clients $(57 \%)$ felt that there was enough privacy during their consultation with the service providers.

Most of the clients interviewed had not visited any other health facility for services in the past twelve months. This means that the only experience they have is at the facility where they were interviewed. Their responses should be interpreted with caution as they have no better or worse experiences to compare this visit with.

More than $70 \%$ of the clients $(73 \%$ and $88 \%$ for $\mathrm{MCH}$ and FP clients, respectively) felt the service provider listened to their concerns. However, only $38 \%$ and $59 \%$ of $\mathrm{MCH}$ and family planning clients, respectively, said that the service provider gave them an opportunity to ask questions that they thought were important. For those who had the chance to ask questions, the majority felt that the responses they received were satisfactory.

\section{b) Clinical assessment of clients}

During this study, a trained interviewer observed and noted what occurred during the interaction between the clients and the service providers using a checklist. The checklist covered all the major topics outlined in the Botswana Family Planning General Policy Guidelines and Service Standards manual. ${ }^{24}$ The checklist included sections on history taking, examination, IEC and counseling. The information obtained through this checklist was used to assess the quality of history taking, examinations and information given to the clients. ${ }^{14}$

\footnotetext{
${ }^{2} 3$ See L. Ndhlovu, Op. Cit.

24 Botswana FP Policy Guidelines and Service Standards manual Op. Cit
} 
Understanding clients' needs: Understanding clients' family planning needs is an important component of the assessment of a client seeking these services. This is achieved by asking clients about their sexual relations, risk factors for ST1s, reproductive intentions, experiences with contraceptive use and their sociodemographic characteristics. The information obtained guides all the next steps in the provision of family planning services. Table 5 shows that steps undertaken to understand clients' needs were better for the new family planning clients compared to the repeat clients. Breast-feeding status, marital status, method preference, knowledge of contraceptive methods and past contraceptive practices were enquired about in more than $50 \%$ of the consultations with new family planning clients. However, desired timing of next birth, history of symptoms/signs of STIs and clients' concerns about STIs were asked about for less than $20 \%$ of the new family planning clients.

Table 5. Understanding clients' family planning needs

\begin{tabular}{|l|c|c|}
\hline \multirow{2}{*}{ Item } & Percent of clients asked \\
\cline { 2 - 3 } & New Clients N=74 & Revisit Clients N=326 \\
\hline & 42 & 10 \\
\hline $\begin{array}{l}\text { If the client wanted more children in } \\
\text { future or not }\end{array}$ & 16 & 7 \\
\hline Discussed timing of next birth & 60 & 16 \\
\hline Client's marital status & 51 & $*$ \\
\hline Past contraceptive use & 74 & $*$ \\
\hline Method preference & 78 & 3 \\
\hline Concerns about specific methods & 47 & 1 \\
\hline $\begin{array}{l}\text { Number of sexual partners in past one } \\
\text { year }\end{array}$ & 8 & \\
\hline $\begin{array}{l}\text { If the client has and/or had } \\
\text { symptoms/signs/treatment suggestive of } \\
\text { STD's }\end{array}$ & 19 & 10 \\
\hline $\begin{array}{l}\text { If client has any concerns about STDs or } \\
\text { HIV/AIDS }\end{array}$ & 19 & 21 \\
\hline $\begin{array}{l}\text { If client was to change or stop using } \\
\text { method }\end{array}$ & $*$ & 59 \\
\hline It client has problems with method & $*$ & \\
\hline$*$ Not included on checklist & \multicolumn{2}{|l|}{} \\
\hline
\end{tabular}

The data from this study also show that discussions about timing of next birth, breast-feeding status and client's concerns were discussed with less than $20 \%$ of the repeat clients. Only $21 \%$ of the repeat clients were asked whether they wanted to change their methods. An even smaller number were asked about previous or current STD symptoms. However, the majority (59\%) of the repeat clients were asked if they had any problems with the method they were currently using. These data show that little effort is made by service providers to look for any changes that might have taken place in the repeat clients' social and medical experiences in between clinic visits. 
Information on a client's sexual behavior is important in deciding the contraceptive advice to be given to a client. For example, clients whose sexual behavior increases their risk for STI and HIV/AIDS should not be advised to use the IUCD while those choosing to use non-barrier methods should be advised on dual contraception. Data from the study show that only $8 \%$ and $3 \%$ of the new and repeat family planning clients, respectively, were asked about the number of sexual partners in the past year. By not enquiring about and/or discussing the client's sexual behavior, the staff are overlooking important information for assisting the client to select an appropriate contraceptive method.

History taking also includes identifying medical contraindications to contraceptive use. This involves asking about past and current medical history of the client. Apart from concerns about general medical issues, there are specific conditions asked about routinely for all fan-family planning clients. Results from the study show that less than $50 \%$ of the new and repeat family planning clients were asked about, abdominal pains and genital itching. Medical and family history was asked for in less than $25 \%$ of the repeat clients (Figure 25 ).

Clinical procedures performed for family planning clients: The Botswana Family Planning General Policy Guidelines and Service Standards manual has laid down a set of clinical procedures to be carried out for new and repeat family planning clients. Findings from this study show that except for BP measurements and weight, staff rarely carry out the procedures outlined in the service manual (Figure 26).

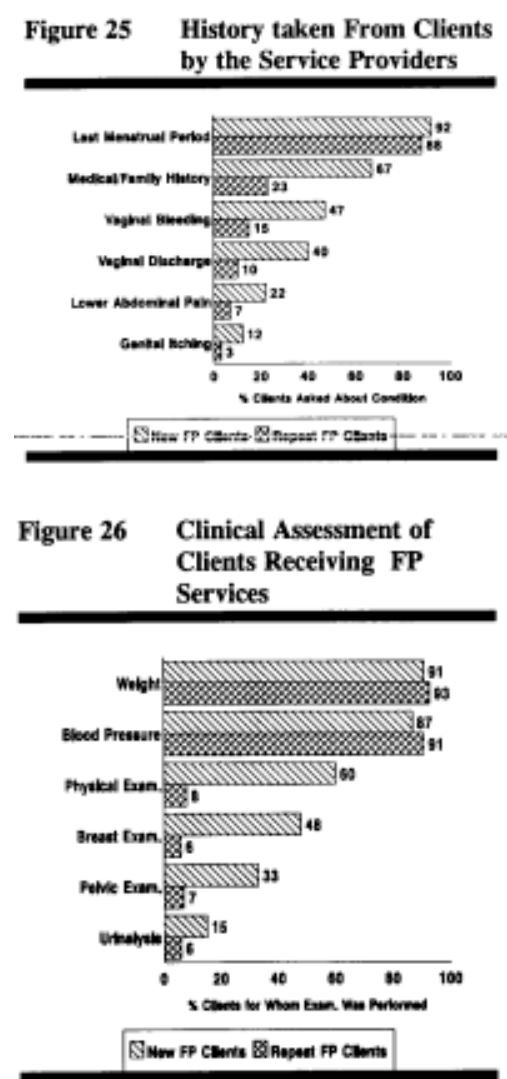

Using the observation checklist, it was observed that more than $85 \%$ of the new and repeat family planning clients had their weight and blood pressure taken. Although most of the clients had their BP measured, it is important to note that this was not done for $13 \%$ of the new clients. Physical examination was done in $60 \%$ of new clients and in only $8 \%$ of repeat clients. Pelvic examination was carried out for $33 \%$ and $7 \%$ of new and repeat clients, respectively. 
Breast examination is a simple procedure used to identify breast lumps early enough to initiate therapy. The procedure is now recommended not only for family planning clients but all women in the reproductive age group. During this study, it was found that breast examination was performed for only $48 \%$ and $6 \%$ of the new and repeat family planning clients, respectively. This represents many missed opportunities to screen clients for a condition that is one of the leading causes of mortality among women.

Pelvic Examination: A pelvic examination can be frightening and anxiety provoking for clients. It is important that clients be informed about the procedure before it is performed and the findings explained to the client in a language that they understand. Pelvic examinations were observed for 47 family planning clients. Many of the clients who had a pelvic examination were not informed about the procedure before it was performed or the findings after the procedure. Although pelvic examinations are supposed to be aseptic procedures, the observers could not conclude that sterile speculums and gloves were used in $16 \%$ and $13 \%$ of the procedures, respectively. The service providers did not wash their hands before and after the procedures in more than $30 \%$ of the procedures observed. When staff do not follow aseptic procedures when performing pelvic examination, they increase the risk of cross infections during these procedures.

The results from this study show that history taking and clinical evaluation of clients is rarely done following the $\mathrm{MOH}$ recommendations. Even when it is done, there is a difference between the proportion of new and repeat clients who are properly assessed. The difference may be based on the incorrect belief that once clients start using family planning methods, there are no changes in their social and medical experiences. This practice may mean a missed opportunity for clients to get properly examined. However, it is important to note that the need to obtain various types of information from repeat clients will depend on the reasons for the visit, the timing and the records available from previous visits.

\section{c) Information given to clients}

During the study, the researchers interviewed 66 new family planning clients who accepted to use a method and 38 repeat clients who changed to a new method. The information given by the providers to these clients about their new methods was used to assess the quality of information clients receive when they visit the health facility for family planning services. Figure 27 shows the types of information given to clients about the methods they accepted to use during the observed clinic visit.

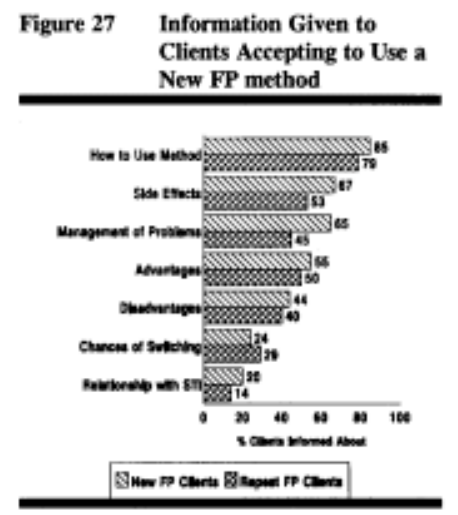


These data show that $85 \%$ and $79 \%$ of new and repeat clients, respectively, were told how to use the method of their choice. More than half of the clients were told about the advantages, side effects of the method and management of problems arising from use of the method. Knowledge of the potential side effects, disadvantages and what to do in case the client experiences problems with the method reduces the rate of discontinuation among clients. Very few new or repeat clients were informed about the possibility of switching methods or the relationship of the method they chose to use with STIs. Generally, repeat clients changing to a new method were less likely to have been informed about the various aspects of the new method compared to the new family planning clients.

Findings from this study show that a health issue different from the one the client had come to seek services for, was discussed with $56 \%$ and $21 \%$ of the new and repeat clients, respectively. STI and HIV/AIDS related topics were discussed with fewer than $30 \%$ of the new clients and $15 \%$ of the repeat clients. Topics related to child health and immunization were discussed with fewer than $15 \%$ of the clients (Figure 28). These findings reveal the many opportunities missed by the services providers to reach out to clients with messages on some important health issues.

Educational materials are rarely used by the service providers during consultation. Overall, IEC materials were used in $35 \%$ and $20 \%$ of consultations with new and repeat clients. Samples of contraceptives were used with $32 \%$ of new clients and $18 \%$ of repeat clients. Other materials used included posters (10\% and 3\% for new and repeat clients, respectively). Figure 29 shows that anatomical models and flip charts were hardly used during consultation.
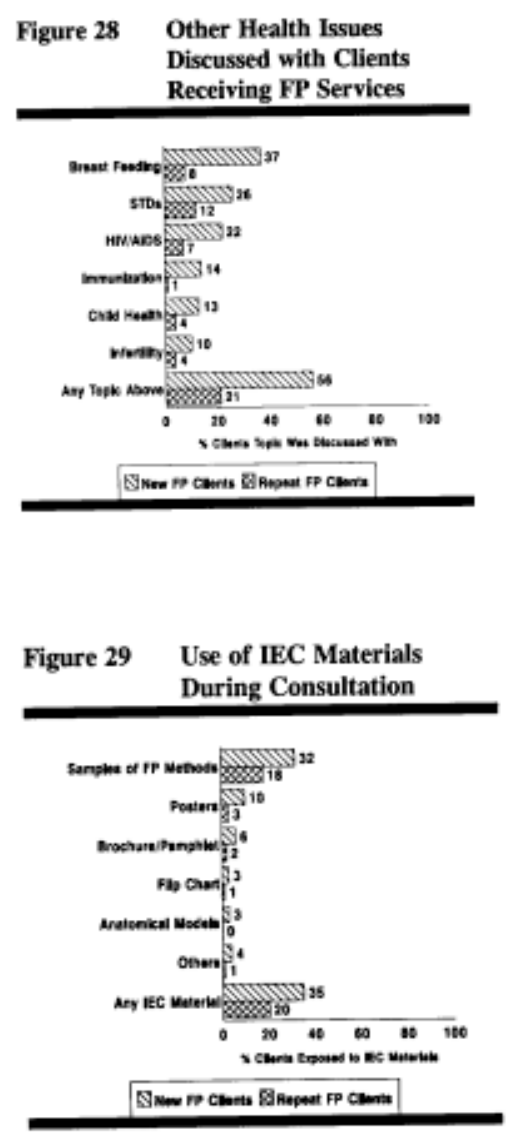

These findings were not surprising since very few of the facilities have any IEC materials. The findings also suggest that service providers may be using nonstandardized approaches to providing IEC to clients. Clients are rarely given any IEC materials to carry home from the health facilities. Less than $15 \%$ of the $\mathrm{MCH}$ and $\mathrm{FP}$ clients had ever taken any IEC materials from the health facilities. Most of the clients (76\% of the $\mathrm{MCH}$ and $78 \%$ of the FP clients) had attended school beyond lower $\mathrm{p} \sim$ This suggests that most of the clients are literate and would benefit from IEC materials. The time spent with service providers is usually very short and clients are often anxious and want to get over with the consultation. This provides little opportunity for a meaningful exchange between the clients and the service providers. 
Providing IEC materials to clients to read at home would go a long way in complementing the clinic visits.

\section{e) Choice of methods}

In addition to having stocks of all program methods, fully informing clients about the range of contraceptive methods enables a program to respond better to the family planning needs in the community. The availability of a method to a client is influenced by many factors. The method may be available at the facility but unavailable to the client due to policies and rules that restrict the service providers from prescribing the method to some groups of people. The service providers may also have their own beliefs and practices that would restrict the availability of the method to clients. Awareness about the existence of the method by the clients is another important factor that would influence the range of methods they can choose from.

Availability of methods: The availability of contraceptive methods has been reported on earlier in this report. Most of the facilities provide the combined pill, progesterone only pill, IUCD, and the injectable. However, spermicides, tubal ligation and Norplant are available at very few of the facilities.

Information given about methods.. When counseling for family planning, service providers are expected to provide information on all the available methods to the client. This would facilitate the clients" ability to make an informed choice of the methods they want to use. Data from this study, show that not all clients get informed about all the available methods of contraception.

The pill was the most commonly mentioned method by the service providers during consultations with the new family planning clients observed in this study. The rest of the methods were mentioned in less than $50 \%$ of the consultations. Despite the large unmet need for permanent methods mentioned earlier, female sterilization was mentioned in only $3 \%$ of the consultations (Figure 30). Service providers are more likely to inform clients about those methods they are more comfortable discussing and are available at the facility. These and other reasons may be responsible for the observations made in this study. Whatever the reasons may be, clients are

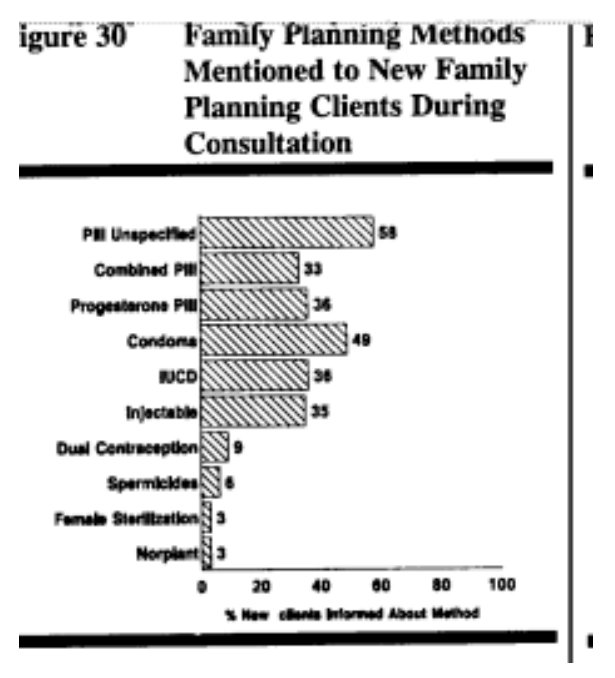
denied access to information that would have helped them to make a better informed choice. 
Methods chosen by clients: Most of the new family planning clients $(89 \%)$ accepted to use a contraceptive method during the visit observed in this study and $(12 \%)$ of the repeat clients changed to a new contraceptive method. Figure 31 shows that more than $50 \%$ of the new clients accepting to use a method and repeat clients who changed to a new method chose to use the pill. More of the repeat clients chose to use the IUCD and the condom ( $13 \%$ and $16 \%$, respectively) compared to the new clients ( $7 \%$ and $0 \%$, respectively).

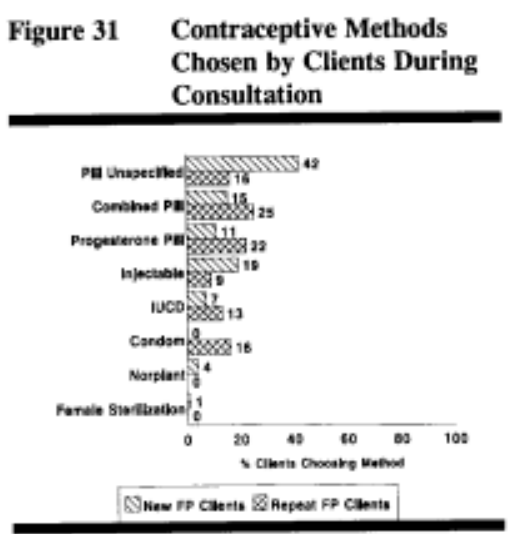

Restrictions to contraceptive use: To have an idea about the existence of restrictions to contraceptive use, staff who had provided the various methods to clients in the three months preceding this study were asked to state their position on some common restrictions (Table 6). More than $90 \%$ of the service providers said that they would not restrict contraceptive use on grounds of marital status and husband's consent. However, it should be noted that $14 \%$ of them said that they would need husbands' consent before issuing condoms to married women. Age emerged as major factor which service providers consider before issuing most of the methods. Most of the service providers (more than 60\%) said that they would restrict the use of the pill, IUCD and the injectable based on age. The mean ages below which service providers would not recommend the use of the pill, IUCD and injectable are 15, 18 and 25 years, respectively. Similarly, $63 \%$ and $70 \%$ of the service providers said that they would restrict the use of the IUCD and injectable, respectively, based on number of living children. Most of the service providers who would impose a parity restriction said that they would not recommend the use of IUCD and injectable for women with less than 2 and 3 children, respectively.

Table 6 Restrictions on the use selected contraceptive methods.

\begin{tabular}{|l|c|c|c|c|}
\hline Method & \multicolumn{4}{|l|}{ Percentage of service providers with restriction } \\
\hline Age & $\begin{array}{l}\text { Number of } \\
\text { Children }\end{array}$ & Marital Status & $\begin{array}{l}\text { Husband's } \\
\text { consent }\end{array}$ \\
\hline Pill & 78 & 32 & 1 & 10 \\
\hline Condom & 13 & 4 & 2 & 14 \\
\hline IUCD & 66 & 63 & 2 & 10 \\
\hline Injectable & 76 & 70 & 3 & 12 \\
\hline
\end{tabular}

The Botswana Family Planning General Policy Guidelines and Service Standards published in 1987 specified age limits, marital status, number of children and spousal consent as requirements for various contraceptive methods. The 
responses obtained from the service providers to a large extent reflect the conditions set out in the above guidelines. Most of the recommendations in this manual have since been revised and a newer version reflecting these changes was published in 1994. The service providers will need refresher training on the new guidelines before a change can be seen in their own practices, knowledge and beliefs.

The presence of genital infections, PID, and HIV infection are listed as absolute contradictions to the use of the IUCD in the revised Family Planning General Policy Guidelines and Service Standards manual. Some service providers $(23 \%)$ were not aware that some contraceptive methods are not recommended for clients with symptoms or signs suggestive of ST1s. However, $93 \%$ of the staff who were aware that some contraceptive methods are not suitable for clients with STIs, said that they would not recommend the IUCD to clients with symptoms suggestive of STIs (Figure 32). Although STIs and HIV infections are not listed as absolute contraindications for the other contraceptive

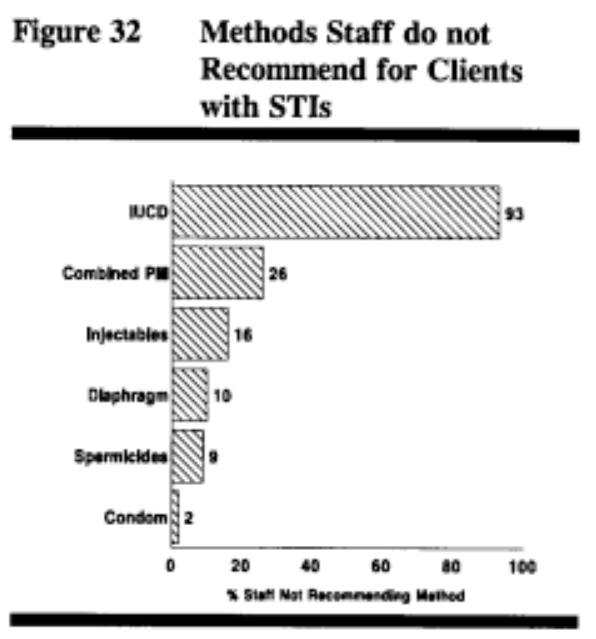
methods, a significant number of staff said that they

would not recommend the pill $(26 \%)$ and the injectable $(16 \%)$ to clients with symptoms suggestive of these infections. Studies elsewhere have shown that the use of hormonal contraceptives reduces the severity of the complications associated with some STIs ${ }^{25}$ Therefore, denying clients with symptoms of ST1s the use of these associated with some STIS. hormonal contraceptives deprives them of these known benefits. Findings from this study also suggest that the service providers may not be aware of the instructions in the service manual about prescribing contraceptive methods for clients with STI and/or HIV infections.

\section{f) Constellation of services}

The Botswana Government adopted primary health care as its central strategy for providing health services to its people in the early 1980s. Within this strategy, the integrated approach is used to provide preventive, rehabilitative and other appropriate curative services at all levels of the national health care system. To the government, integration of the $\mathrm{MCH} / \mathrm{FP}$ services means being able to provide all the service components of $\mathrm{MCH}$ and $\mathrm{FP}$ on daily basis to a family at a single visit. The MCH/FP services are to be provided alongside the other promotive and curative services including STI and I-HV management. Data already presented in the report (Page 24, Figure 21) show the services that were available to clients at the health facilities on the days they were visited for this study. Family planning, child welfare, and $\mathrm{STI}^{15}$

${ }^{2} 5$ Hatcher R.A., Trussell J., Stewart F., et al. (1 994), “Combined Oral Contraceptives: Advantages and indications.' in Contraceptive Technology 16th. Revised Edition 228-233. 
management were available at more than $90 \%$ of the facilities. Antenatal and IHIV/AIDS services were not available to clients at $29 \%$ and $35 \%$ of the facilities, respectively.

The basic immunization services including BCG, Polio, DPT, Measles and Tetanus for antenatal clients were available at more than $85 \%$ of the health facilities. However, a significant number of the facilities providing these services did not have supplies of the vaccines on the day they were visited. Table 7 shows that more than $10 \%$ of the facilities which indicated that they were providing these immunization services did not have supplies of BCG, Polio, and Measles vaccines. Similar proportions had experienced a stockout of the vaccines in the six months preceding this study. Many facilities $(50 \%)$ do not have an EPI refrigerator. This may explain why some facilities did not have vaccines on the day of the visit.

Table $7 \quad$ Availability of immunization services.

\begin{tabular}{|l|c|l|l|}
\hline $\begin{array}{l}\text { Type of } \\
\text { immunization }\end{array}$ & $\begin{array}{l}\text { Percentage of } \\
\text { facilities providing }\end{array}$ & $\begin{array}{l}\text { Percentage of facility } \\
\text { providing without } \\
\text { supplies on day of } \\
\text { visit }\end{array}$ & $\begin{array}{l}\text { Percentage of } \\
\text { facilities who } \\
\text { experienced } \\
\text { stockout in } \\
\text { 6 months }\end{array}$ \\
\hline BCG & 87 & 16 & 14 \\
\hline POLIO & 90 & 22 & 32 \\
\hline DPT & 91 & 8 & 9 \\
\hline Measles & 86 & 12 & 13 \\
\hline
\end{tabular}

The need for multiple services exists among clients receiving $\mathrm{MCH} / \mathrm{FP}$ services. A significant proportion $(29 \%)$ of the clients whose primary reason for visiting the clinic was to receive family planning service obtained other services during the same visit. Child welfare and curative services were provided to $\mathrm{I} I \%$ and $13 \%$, respectively, of clients who received another service besides family planning services (Figure 33). These findings suggest that women visiting the health facilities often do so for more than one reason. If services are provided on different clinic days, such clients must make separate visits with all the attendant costs. There is therefore a need for the government to strengthen its integration activities and to

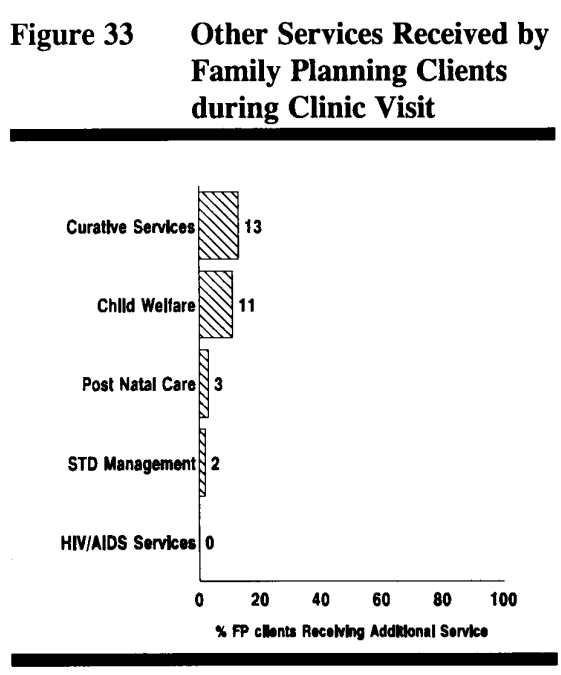
facilitate availability of multiple services at all times. 


\section{Need for reproductive health services.}

Unmet contraceptive needs: The vast majority (95\%) of the clients receiving $\mathrm{MCH}$ services knew of at least one way of preventing and/or delaying a pregnancy. More than $80 \%$ knew of the pill, IUCD and the injectable. However, $27 \%$ did not know that the condom could be used to prevent and/or delay a pregnancy. Less than $10 \%$ of the $\mathrm{MCH}$ clients mentioned female sterilization and spermicides as methods that are used to prevent pregnancy. These data suggest that many women are not aware of all the available contraceptive methods.

Although the majority (79\%) of the women receiving $\mathrm{MCH}$ services at the health facilities had used at least one contraceptive method in the past, a smaller number $(37 \%)$ were currently using a method at the time of this study. Figure 34 shows that the pill is the most commonly used method followed by the condom and injectable by those clients who were currently using any contraceptive method. The figure also shows that only seven (1\%) of the $\mathrm{MCH}$ clients were currently using female sterilization or the IUCD for family planning. This figure is very low given the findings from this study that $47 \%$ of the $\mathrm{MCH}$ clients did not want to have any more children in the future. The pattern of contraceptive use observed among clients visiting these health facilities is not necessarily the same as that in the general population.

The 327 clients receiving $\mathrm{MCH}$ services who said that they would like to have a child in the future were asked to state when they would like to have their next child (Figure 35). Only 68 (21\%) said that they would like to have the next child within the next 12 months. The majority (53\%) were not planning to have a child within the next two years. The "other response" includes answers like; it is God who plans, the husband or spouse decides and I do not know. Although, most of these women did not want to have their next child within the next twelve months, many were not using any contraceptive method. For example of the 173 women who wanted to delay their next birth beyond two years, only $43 \%$ were using a family planning method.
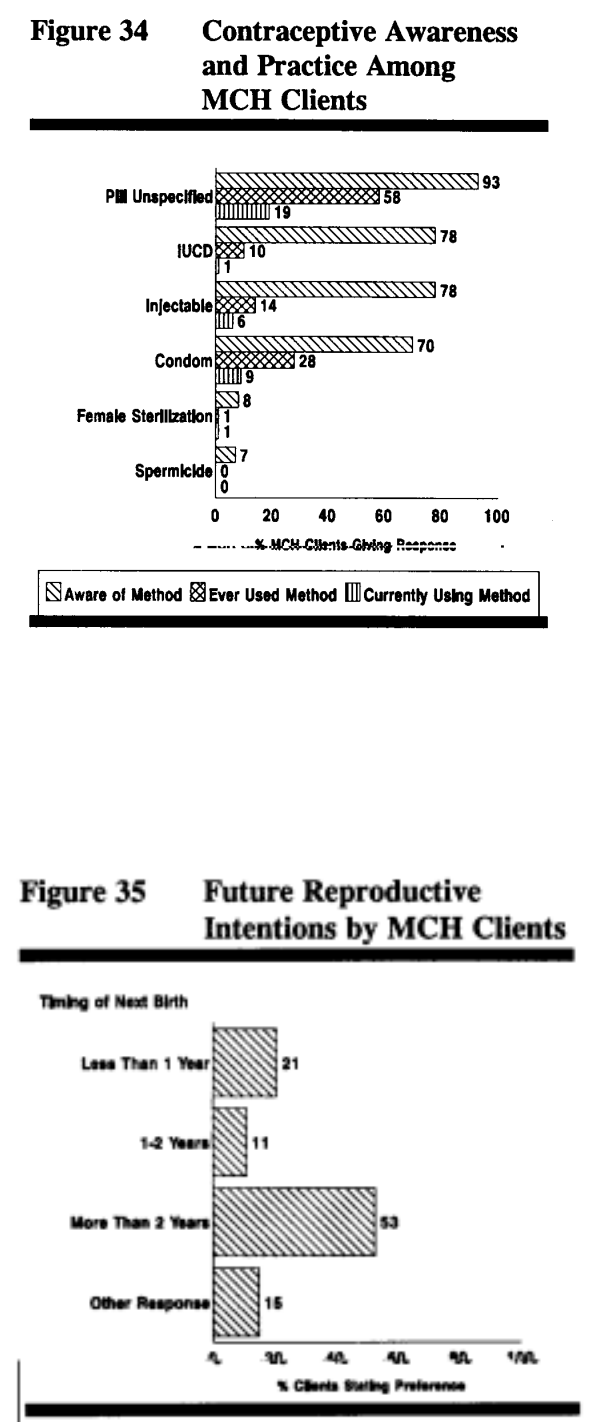

These findings suggest that there is an unmet need for contraceptive services among clients receiving $\mathrm{MCH}$ services at the health facilities. 
The majority (63\%) of clients who received $\mathrm{MCH}$ services during this study were not using any family planning method. However, only $25 \%$ of the $\mathrm{MCH}$ clients who were not using family planning remembered seeing or hearing anything about family planning during their visit to the health facility. This represents a major missed opportunity to inform these clients about family planning while they were visiting the health facility for other services.

Another indicator of the unmet need for contraceptive services is the number of women who get pregnant when they did not plan to do so. Data from the study show that this is common among the clients. Nearly fifty percent of clients receiving $\mathrm{MCH}$ and FP services had experienced at least one pregnancy that they had not planned for. Most of the $\mathrm{MCH}$ and FP clients (94\% and 98\%, respectively) reporting an unplanned pregnancy in the past said that they chose to continue with the pregnancy to delivery.

The information available from this study suggests that there are unmet needs both for long-term/permanent and spacing methods of contraception among women receiving $\mathrm{MCH}$ services at the health facilities. The data also suggest that service providers are not taking advantage of the presence of these clients at the facilities to educate, counsel and motivate them for family planning services.

Need for STI and HIV/AIDS services: Earlier in this report it was shown that STI's are discussed with few clients during consultations. It was therefore not surprising that both $\mathrm{MCH}$ and family planning clients had limited knowledge of symptoms associated with ST1s. The poor knowledge of symptoms and modes of transmission for ST1s and HIV/AIDS is an indication of the unmet need for IEC on ST1s and IUV/AIDS among these clients. All the $\mathrm{MCH}$ and FP clients included in the study were first asked if they knew of any diseases that are transmitted through sexual intercourse. Those clients who said that they knew of such diseases were then asked to spontaneously name the symptoms associated with them.

Table 8 shows that lesions/sores were the most commonly mentioned symptoms of STI's by both MCH and family planning clients followed by loss of weight which was mentioned by $34 \%$ and $33 \%$ of $\mathrm{MCH}$ and fan-family planning clients respectively. Abnormal vaginal discharge was mentioned by $26 \%$ and $30 \%$ of $\mathrm{MCH}$ and family planning clients, respectively. Less than $25 \%$ of the clients mentioned the rest of the symptoms. There was no difference in knowledge of symptoms between clients who received $\mathrm{MCH}$ and FP services.

Generally, this data shows that $\mathrm{MCH} / \mathrm{FP}$ clients have poor knowledge of the symptoms for ST1s. As was mentioned earlier, the syndromic approach to STI diagnosis and treatment is the one that has been adopted and recommended by the STD/AIDS control program. For this approach to be used successfully, clients have to know the symptoms of the common ST1s as this will help greatly during history taking. Knowledge of these symptoms win also influence the health seeking behavior of the 
clients. If the clients do not associate the symptoms they may have with ST1s and/or HIV/AIDS, it is unlikely that they will seek medical attention.

Table 8. Knowledge of symptoms and signs of STDs

\begin{tabular}{|l|c|c|}
\hline \multirow{2}{*}{ Symptoms and Signs } & \multicolumn{2}{l|}{$\begin{array}{l}\text { Percentage of clients naming } \\
\text { symptoms }\end{array}$} \\
\cline { 2 - 3 } & $\begin{array}{l}\text { MCH Clients } \\
\text { N=721 }\end{array}$ & $\begin{array}{l}\text { FP Clients } \\
\text { N = 385 }\end{array}$ \\
\hline Genital lesions/sores & 46 & 49 \\
\hline Loss of weight & 34 & 33 \\
\hline Abdominal vaginal discharge & 26 & 30 \\
\hline Diarrhoea of long duration & 21 & 21 \\
\hline Pain on passing urine & 19 & 25 \\
\hline Genital itching & 15 & 17 \\
\hline Abnormal growth in genital area (Warts) & 9 & 12 \\
\hline Lower abdominal pain & 7 & 9 \\
\hline Urethral discharge & 5 & 8 \\
\hline Pain during sexual intercourse & 2 & 3 \\
\hline Abnormal vaginal bleeding & 1 & 2 \\
\hline
\end{tabular}

Knowledge of modes of transmission of any disease will influence behavioral change by individuals. The clients' knowledge of the modes of transmission for HIV other than through sexual intercourse was poor (Figure 36). The majority $(60 \%$ and $56 \%)$ of the $\mathrm{MCH}$ and $\mathrm{FP}$ clients, respectively, did not know of any other ways that HIV is spread other than through sexual intercourse. Although most of the clients were in the reproductive age group, more than $80 \%$ did not know that HIV infection can be transmitted from the mother to the unborn child. Only $16 \%$ and $22 \%$

Figure 36 Awareness about Modes of Transmission for HIV Infection

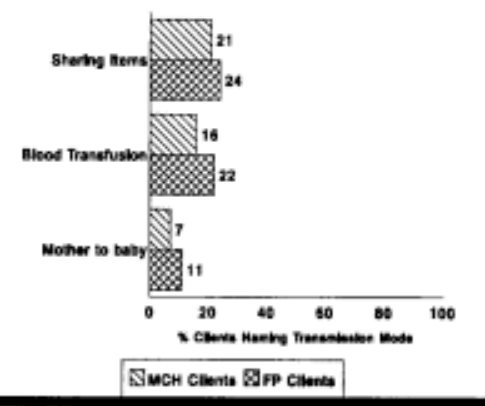
of the $\mathrm{MCH}$ and FP clients, respectively, mentioned blood transfusion as one of the ways that HIV infection can be transmitted. 
The majority of clients interviewed had not had a new sexual partner in the last 12 months. Figure 37 shows that only I I\% and $20 \%$ of $\mathrm{MCH}$ and family planning clients had a new sexual partner in the 12 months before the study. More than two-thirds of $\mathrm{MCH}$ and family planning clients reporting a new sexual partner in the twelve months preceding the study said that they had used condoms in the first sexual encounter with the new partner. Although the numbers are small, the data suggest that most of the clients who have new sex partners take precautions during the first sexual

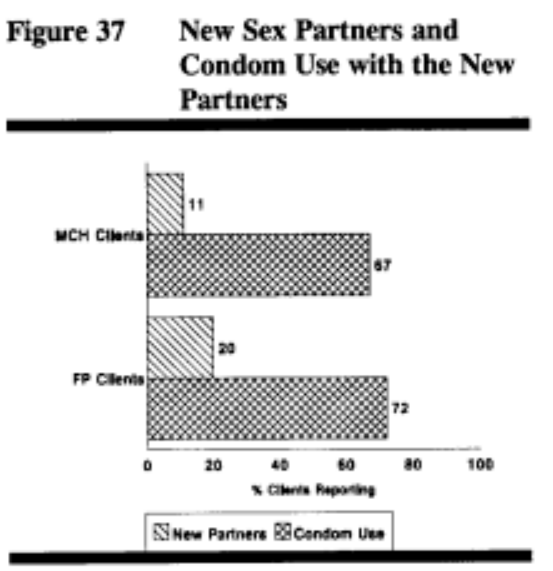
encounter. This is a good indication of future use of the condom in such relationships since it is more difficult to negotiate condom use in established relationships.

\section{Conclusions and programmatic recommendations}

The participants in the data interpretation and national dissemination workshops were requested to draw conclusions and make programmatic recommendations based on the findings from the Situation Analysis Study. The overall conclusion from the two workshops was that given the high client loads, training backgrounds and sometimes the lack of adequate equipment and supplies, the service providers are putting much effort into providing the $\mathrm{MCH} / \mathrm{FP}$ services at their health facilities. However, the quality of services being provided needs improvement if they are to respond adequately to the clients' reproductive health needs. The specific conclusions and recommendations are presented below.

\section{Infrastructure}

The study found that the current infrastructure does not give clients adequate privacy during the consultations. This is mostly due to the architectural designs of the current facilities which did not take privacy into consideration. In addition poor use of the available space and poor client flow has also contributed to the poor privacy clients experience during consultations. It was also found that some basic amenities are lacking at some facilities. Therefore:

- As a short-term measure, it was recommended that the client flow and use of the available space at the various health facilities should be reviewed to improve on the privacy provided to clients during consultations.

- The long-term recommendation was that renovations of the available physical facilities should be carried out taking into account issues related to privacy. In the future, all new health facilities should be designed with privacy in mind. This will be 
greatly helped if the design is done in consultation with the service providers and potential users of the facilities.

The participants noted that many facilities lacked a functioning source of energy. They recommended that the program should ensure that all the facilities have access to a functioning source of energy at all times. Solar electricity has been found very useful and reliable in those facilities where it is available. If this is not possible, alternative sources like generators, CADAC lamps and working torches with batteries should be provided to these facilities.

\section{Equipment and supplies}

Although most of the facilities have the basic equipment required to provide the basic $\mathrm{MCH} / \mathrm{FP}$ and STI/HIV/AIDS services, there were areas that needed some attention. The participants felt that some equipment like blood pressure and weight measuring equipment were of a poor quality leading to frequent breakdowns. They also said that they lacked back up supplies, spare parts and the skills to service these equipment. Therefore:

- All facilities should be provided with spare equipment to be used when there are breakdowns.

- The staff should be trained in the basic maintenance of the equipment and provided with the spare parts required to carry out regular servicing of the equipment.

- The District Health Teams should review quantity and functional status of the available equipment and supplies at the health facilities regularly at intervals not greater than six months.

- The purchase of the equipment and supplies should be done in consultation with service providers. This will help in identifying those equipment and supplies that are of good quality based on the service providers' experiences.

\section{Logistics management for contraceptive and other supplies}

Although all health facilities are expected to keep stocks of contraceptives and other essential supplies adequate for two months at any given time, many facilities were found to be lacking supplies of condoms, IUCDs and vaccines on the day of the survey. Many facilities were also found to have expired contraceptives in their stores. Besides lacking supplies on the day of the survey, many facilities reported that they had experienced stockouts of these commodities in the six months preceding this study. The study also found that stockbooks were not well maintained at many facilities while commodities were not being stored according to the recommended " first expiry first out" principle. Therefore: 
- There is a need to strengthen logistics management at the health facility level. This should be in the form of refresher training for all staff in commodity and supplies management,

- Supervisors should check on the stocks available, storage facilities and the completeness of the stockbook during supervisory visits to the health facilities.

- A checklist to determine the quantities of supplies available and their expiry status should be prepared and made part of the monthly reporting requirements.

\section{Staff preparedness to provide MCH, FP, STI and HIV/AIDS services}

Despite the training that the service providers have received in providing the basic MCH,FP, STI and HIV/AIDS services, they still lacked adequate skills to provide good quality services in all these areas, especially STI and HIV/AIDS. The participants also said that the Family Planning Policy Guidelines and Service Standards Manuals are not available to most of the services providers. Therefore:

- There is need to review the training curricula for nurses and FWEs to expand and improve the content to include recent advances in STI and HIV/AIDS management.

- Apart from training the service providers in the management skills for the individual services, there is a need to train them on how to provide these services using the integrated approach.

- There is a need to develop a mechanism for transferring skills acquired by the few staff trained in the provision of these services to their colleagues at the workplace since training all the service providers through the current approaches is not possible. This can be in the form of on-the-job training by the staff who have been trained in the relevant fields.

- The long-term recommendation is to review the pre-service training curricula for the service providers to include training in the provision of MCH, FP, STI and HIV/AIDS services.

- A mechanism for ensuring that all service providers have access to and are trained on the up-to-date Policy Guidelines and Service Standards manuals needs to be developed and institutionalized- 


\section{Laboratory diagnostic facilities}

Although the BOTSPA project and the national STD/AIDS control programs are emphasizing the use of "the syndromic approach to diagnose and treat ST1s, the need for some basic laboratory facilities exists. For example all antenatal clients are to be screened for syphilis, women receiving FP services require regular Pap Smear screening, and HIV testing is required for many clients. Currently, laboratory facilities are found at very few facilities and there is little coordination of activities with the health facilities. Delays in obtaining results often lead to failure to provide treatment on time and clients have to make several clinic visits. Therefore:

- There is a need to establish more reference laboratory facilities in order to increase accessibility to the basic laboratory services.

- The clinic staff should be trained in the use of some simple basic laboratory tests like RPR tests for syphilis which could be carried out at the health facility level.

- There is a need to coordinate the laboratory and health facility activities to avoid delays in obtaining specimens and results.

\section{Information, Education and Communication materials and activities}

IEC materials and activities are generally lacking at most of the facilities. Even where the IEC materials are available, they are hardly used by the staff during consultations. The participants felt that many of the service providers are not competent in using the available materials. Therefore:

- Operations research should be undertaken to identify and develop appropriate and target oriented IEC messages and approaches to be used during IEC activities.

- IEC materials should be made available at the health facilities for use by the service providers and for clients to take home.

- The service providers should be trained in carrying out IEC activities and the use of the available IEC materials.

- Group health talks at (he health facilities should be re-established and strengthened.

- Improve the coordination of IEC activities at all levels including the Primary Health Care Department at the Ministry of Local Government, the District Health Teams and the Family Health Division. 
- Make audiovisual equipment available in the waiting areas/rooms at the health facilities to be used for IEC activities. Clients can listen/watch IEC activities on these equipment while waiting to receive their services.

\section{Quality of services provided}

The quality of care provided to clients at the health facilities needs to be improved. There is no standardized approach to history taking, clinical assessment and provision of services. Although the Division of Family Health has revised the Family Planning Policy Guidelines and Service Standards manual, this has not been circulated. Therefore:

- The revised MCH/FP service guidelines should be disseminated and circulated to all the service providers. It was recommended that the District Health Teams should be responsible for organizing these activities and any future dissemination of new information through workshops and other appropriate strategies.

- Guidelines for IEC activities and counseling to be used by the service providers should be developed and disseminated urgently.

- The current MCH and FP case (client) cards do not provide for the collection and recording of client information related to ST1s and HIV/AIDS. These should be revised and made available for use at the health facilities.. At the time of the study, the BOTSPA Project had started to revise these cards and it was recommended that they continue to lead this activity.

- Mechanisms to involve the community in the design, planning and provision of the services should be developed and implemented at the health facility level.

- The current range of methods offered at the health facilities is not wide enough to facilitate choice. There is a need to broaden the method mix.to include spermicides and the long-term methods.

\section{Integration of services}

Although the policy of the government is to provide all the MCH, FP and curative services to a client at a single clinic visit, the study found that many health facilities do not provide antenatal, postnatal, STD and HIV/AIDS services on a daily basis. The study also found that knowledge of ST1s and HIV/AIDS was poor among clients receiving $\mathrm{MCH}$ and FP services yet very few clients had been given any information about these conditions during the clinic visit. Many of the clients were not aware that they could get STD and HIV/AIDS services at the facilities they had visited. The majority of the clients receiving $\mathrm{MCH}$ services from the health @ties were not using a contraceptive method and many did not want to get pregnant in the next two years; yet very few of them heard or saw anything about family planning during the clinic visit. Based on these and other findings from the study, the participants concluded that integration of services is still lacking in the program. Therefore: 
- There is a need to identify and address those issues that are preventing many of the health facilities and service providers from providing integrated $\mathrm{MCH}, \mathrm{FP}, \mathrm{STD}$ and HIV/AIDS services on a daily basis.

\section{Management and supervision}

Although many health facilities are getting supervision and support visits from the DHT, the activities carried out during these visits are not well coordinated. There are no supervision checklists to help standardize the activities carried out by the supervisors. This makes it difficult to monitor and compare the performance of the different health facilities. Therefore:

- There is a need to strengthen the role of the District Health Teams in providing supervision and support to the health facilities.

- A supervision checklist, outlining the objectives of supervision, the activities to be carried out and the processing of the information collected, should be developed. The BOTSPA project has started this process and will continue to lead this activity. 